\title{
CaSR participates in the regulation of vascular tension in the mesentery of hypertensive rats via the PLC-IP 3 /AC-V/cAMP/RAS pathway
}

\author{
WENWEN ZHANG ${ }^{1,2 *}$, RUIXIA SUN ${ }^{1 *}$, HUA ZHONG $^{1}$, NA TANG $^{1}$, \\ YONGMIN LIU ${ }^{1}$, YONGLI ZHAO ${ }^{1}$, TIAN ZHANG ${ }^{1}$ and FANG HE ${ }^{1 *}$ \\ ${ }^{1}$ Department of Pathophysiology, Key Laboratory of Education Ministry of Xinjiang Endemic and Ethnic Diseases, \\ Medical College of Shihezi University; ${ }^{2}$ Department of Emergency and Critical Care Medicine, \\ The First Affiliated Hospital of Medical College of Shihezi University, Shihezi, \\ Xinjiang Uygur Autonomous Region 832008, P.R. China
}

Received January 23, 2019; Accepted July 12, 2019

DOI: $10.3892 / \mathrm{mmr} .2019 .10620$

\begin{abstract}
Hypertension is a cardiovascular disease that severely impairs human health; however, its specific etiology and pathogenesis are complex. The present study investigated the effects of the calcium sensing receptor (CaSR) on vascular tone in spontaneously hypertensive rats (SHRs), and clarified the role and mechanism of CaSR in regulating this property with respect to the phospholipase C (PLC)-inositol 1,4,5-triphosphate $\left(\mathrm{IP}_{3}\right)$ /adenylate cyclase- $\mathrm{V}(\mathrm{AC}-\mathrm{V}) /$ cyclic adenosine monophosphate (cAMP)/renin-angiotensin system (RAS) pathway in these animals. CaSR protein expression in the mesenteric artery (MA) of rats and CaSR protein expression in SHRs were significantly reduced. Based on wire myography studies, vasoconstriction was significantly augmented and vasodilatation was attenuated in SHRs, and this effect was endothelium-independent. The CaSR calcimimetic NPSR568 and inhibitor NPS2143 reduced vasoconstriction and enhanced vasodilation in SHRs. Furthermore, pretreatment with $\mathrm{PLC}-\mathrm{IP}_{3} / \mathrm{AC}-\mathrm{V} / \mathrm{cAMP} / \mathrm{RAS}$ pathway blockers significantly reduced the vasoconstriction response and enhanced the vasodilator response in SHRs and Wistar-Kyoto rats (WKY), and these effects were partially dependent on the endothelium. Additionally, pretreatment with CaSR inhibitors were determined to cooperate with the PLC-IP $/$ /AC-V/cAMP/RAS pathway inhibitors to significantly reduce vasoconstriction and enhance vasodilation in SHRs and WKY. Our results demonstrated that CaSR is functionally
\end{abstract}

Correspondence to: Dr Fang He, Department of Pathophysiology, Key Laboratory of Education Ministry of Xinjiang Endemic and Ethnic Diseases, Medical College of Shihezi University, 59 North 2nd Road, Shihezi, Xinjiang Uygur Autonomous Region 832002, P.R. China E-mail: fangf2002shz@126.com

${ }^{*}$ Contributed equally

Key words: mesenteric artery, calcium-sensing receptor, hypertension, vascular tension, renin-angiotensin system expressed in the MA of SHRs, and that CaSR expression is decreased in SHRs. Additionally, vasoconstriction was enhanced while vasodilatation was attenuated in SHRs; these processes were determined to be endothelium-independent. CaSR is involved in the regulation of blood pressure and vascular tension in SHRs and WKYs. In association with mechanistic differences, this effect was proposed to be partially endothelium-dependent and mediated by the PLC-IP 3 /AC-V/cAMP/RAS pathway.

\section{Introduction}

More than 1.5 billion people worldwide are affected by hypertension, yet its etiology and pathogenic mechanisms remain unclear $(1,2)$. Among these patients, those with essential hypertension (EH) account for $90-95 \%$ of the total hypertensive patient population (3). EH is a polygenic genetic disease mediated by interactions between genetic and environmental factors, and is a risk factor for the development of various cardiovascular and cerebrovascular diseases (such as myocardial infarction, atherosclerosis and cerebral apoplexy) (4). The key component of EH morbidity is the blood vessels (5), and the direct etiological factor comprises an increase in peripheral vascular resistance, which leads to endothelial dysfunction in the heart, brain, kidney, and surrounding blood vessels (5).

It has been reported that low levels of dietary $\mathrm{Ca}^{2+}$ represent a significant risk factor for hypertension, whereas the intake of appropriate amounts of $\mathrm{Ca}^{2+}$ effectively lowers blood pressure (BP), as well as the incidence and mortality of cardiovascular disease $(6,7)$. This has been confirmed by animal studies (8). Calcium sensing receptor (CaSR) is the receptor for extracellular $\mathrm{Ca}^{2+}$, and a member of the $\mathrm{C}$ subfamily of the G protein coupled receptor (GPCR) family. In 1993, Brown et al (9) first cloned CaSR from the bovine parathyroid gland. CaSR is mainly distributed in the parathyroid gland, bone, kidney, intestines and other tissue cells (such as hepatocytes, vascular endothelial cells and vascular smooth muscle cells (VSMCs) related to calcium transfer and calcium homeostasis regulation, and it plays a key role in maintaining calcium homeostasis $(10,11)$. When the extracellular calcium 
concentration $\left(\left[\mathrm{Ca}^{2+}\right]_{\mathrm{o}}\right)$ rises, CaSR is activated. With Gaq as a mediator, CaSR increases the levels of inositol 1,4,5-triphosphate $\left(\mathrm{IP}_{3}\right)$ and diphosphoglycerate through phospholipase $\mathrm{C}$ (PLC), inducing an increase in the intercellular calcium concentration $\left(\left[\mathrm{Ca}^{2+}\right]_{\mathrm{i}}\right)$ and inhibiting parathyrin $(9,12)$. Subsequently, $\left[\mathrm{Ca}^{2+}\right]_{\mathrm{o}}$ is restored to normal levels (13).

In research on the pathogenesis of hypertension, the renin-angiotensin system (RAS) is important, and it is the most important regulatory factor in vivo. Renin is the first rate-limiting enzyme of the RAS, and cyclic adenosine monophosphate (cAMP) functions as a key effector in this system (14). Existing research shows that $\left[\mathrm{Ca}^{2+}\right]_{0}$ and $\left[\mathrm{Ca}^{2+}\right]_{i}$ are inversely proportional to renin secretion by the juxtaglomerular apparatus (15). Furthermore, the mechanism associated with this is related to the increase in $\left[\mathrm{Ca}^{2+}\right]_{\mathrm{o}}$ through increasing $\left[\mathrm{Ca}^{2+}\right]_{\mathrm{i}}$ and/or the activity of calmodulin $(\mathrm{CaM})$, and inhibiting adenylate cyclase-V (AC-V) so that cAMP production is decreased; it is also related to the inhibition of renin release $(16,17)$. In freshly isolated and primary cultured granulocytes of the glomerulus, CaSR is activated, and the ryanodine receptor is also activated via the $\mathrm{G}$ protein-PLC-IP 3 pathway, which causes an increase in $\left[\mathrm{Ca}^{2+}\right]_{\mathrm{i}}$, the suppression of adenylyl cyclase $\mathrm{V}(\mathrm{AC}-\mathrm{V})$ activity, reductions in CAMP, and the inhibition of renin release (12). Our previous research shows that CaSR participates in the occurrence and development of EH. The increase in BP was found to be related to the low expression of CaSR (18). In addition, BP-mediated regulation of CaSR was identified via activation of the cAMP-RAS pathway (18).

In recent years, with extensive research on CaSR, its prominent effect on the cardiovascular system has caused this protein to receive extensive attention. Of note, CaSR is also expressed in the vasculature. Smajilovic and Tfelt-Hansen (19) reported a rise in $\left[\mathrm{Ca}^{2+}\right]_{0}$ through the activation of CaSR. The mechanism of BP reduction was also found to be linked to the inhibition of RAS activation and consequent vasodilatation. Thus, the changes in $\left[\mathrm{Ca}^{2+}\right]_{0}$ concentration and activity of CaSR have a direct effect on angiotasis and thus influences the BP directly (19). Cow (20) revealed that increasing $\left[\mathrm{Ca}^{2+}\right]_{0}$ and other CaSR calcimimetics (such as neomycin, $\mathrm{Mg}^{2+}$ ) can mediate the vasodilatation or exhibit two-way regulatory effect on the mesenteric artery (MA), coronary artery, renal artery and cerebral artery; the mechanism underlying this phenomenon does not rely on the vascular endothelium (21), the production of nitric oxide (NO) via CaSR activation and/or the effect of endothelium-derived hyperpolarizing factor, and the peripheral and central nervous systems (22-25). The regulation of angiotasis and BP by CaSR are consequences of the involvement of polymolecular and multiple mechanisms (19-25); however, the specific regulatory mechanism is yet to be determined. In addition, whether RAS participates in the regulation of CaSR during angiotasis requires further investigation.

Based on the results of previous experiments and the relationship between $\mathrm{Ca}^{2+}$, RAS, and CaSR, we proposed the following research hypotheses: In spontaneously hypertensive rats (SHRs), CaSR expression is reduced or functional defects lead to a decrease in $\left[\mathrm{Ca}^{2+}\right]_{\mathrm{i}}$ mediated by the $\mathrm{PLC}-\mathrm{IP}_{3}$ pathway, the amelioration of the inhibitory effect on $\mathrm{AC}-\mathrm{V}$, increases in CAMP, the promotion of renin release, and vasoconstriction mediated via the RAS pathway, which are involved in the occurrence and development of hypertension. Thus, the present study aimed to examine the effects of CaSR on the vascular reactivity in hypertensive rats. This mechanism was illustrated with respect to the $\mathrm{PLC}-\mathrm{IP}_{3} / \mathrm{AC}-\mathrm{V} / \mathrm{cAMP} / \mathrm{RAS}$ pathway, and may provide further insight into the prevention of hypertension and the effects of novel therapeutic agents.

\section{Materials and methods}

Animals. In total, 216 male Wistar-Kyoto rats (WKY) and SHRs (age, 12 weeks; weight, 200-300 g) were obtained from Vital River Laboratory Animal Science and Technology Co, Ltd. in Beijing (license no. SCXK2012-0001), and housed in a controlled environment with $48 \pm 2 \%$ humidity at $22 \pm 2^{\circ} \mathrm{C}$ under a $12 \mathrm{~h}$ light/dark cycle. The SHR and WKY were divided into different groups ( $\mathrm{n}=6$ /group), and provided ad libitum access to food and water. The animal study was approved by the Institutional Animal Research Committee of Shihezi Medical University (license no. 2015-041-01), and all animals received humane care in compliance with the Guide for the Care and Use of Laboratory Animals published by the National Institutes of Health (26).

Chemicals and reagents. Phenylephrine (PE; Sigma-Aldrich; Merck KGaA), sodium nitroprusside (SNP; Sigma-Aldrich; Merck KGaA), indomethacin (Cyclooxygenase 2 inhibitor; Sigma-Aldrich; Merck KGaA), EDTA (Sigma-Aldrich; Merck KGaA), dimethyl sulfoxide (DMSO; Sigma-Aldrich; Merck KGaA), acetylcholine (Ach; Apexbio Corporation), MDL12330A (AC-V inhibitor, Apexbio Corporation). NPS2143 (CaSR inhibitor, R\&D Systems, Inc.), NPSR568 (CaSR agonist, R\&D Systems, Inc.). $\mathrm{N}^{\mathrm{G}}$-nitro-L-arginine methyl ester (L-NAME, NOS inhibitor; Selleck Chemicals), U73122 (PLC inhibitor, Selleck Chemicals), 2-aminoethoxydiphenyl borate (2-APB, $\mathrm{IP}_{3}$ inhibitor; Selleck Chemicals), Captopril (CAP, angiotensin-converting enzyme inhibitor, Selleck Chemicals), Losartan [LOS, angiotensin II receptor type 1 (AT1R) inhibitor, Selleck Chemicals]. All of the other chemicals were of reagent grade. Indomethacin, L-NAME, NPS2143, NPSR568, U73122, 2-APB, MDL12330A, CAP and LOS were dissolved in DMSO to prepare stock solutions $\left(10^{-1} \mathrm{~mol} / \mathrm{l}\right)$, with the use of double distilled water prepared into the corresponding working fluid. The other agents were prepared in double distilled water. Studies have shown no notable effects on the tension development of isolated arteries with concentrations of DMSO $<0.2 \%$ (27-29).

Blood pressure measurement. Before the experiment, the BP was measured via the tail cuff method, which included warming the whole animal body in the absence of anaesthesia (BP-96A-L, Softron) (30). Measurements were taken every day for a week, at the same time of day and at a controlled temperature of $30^{\circ} \mathrm{C}$. After the rats had acclimated to the environment, the systolic blood pressure (SBP), diastolic blood pressure (DBP) and mean arterial pressure $(\mathrm{MAP})$ were measured $[\mathrm{MAP}=(\mathrm{SBP}+2 \mathrm{x}$ $\mathrm{DBP} / 3$ ]. The measurements were repeated three times, and the average of the three measurements was calculated.

Western blot analysis. The rats were sacrificed via decapitation under anesthesia with $3 \%$ sodium pentobarbital $(50 \mathrm{mg} / \mathrm{kg}$, intraperitoneal injection). The MA was harvested and then 
lysed. It was then homogenized in RIPA lysis buffer (Beijing Solarbio Science \& Technology Co., Ltd.) supplemented with PMSF (100:1) and centrifuged at $14,000 \times \mathrm{g}$ for $15 \mathrm{~min}$ at $4^{\circ} \mathrm{C}$. The supernatants were collected and the protein concentration was determined using the bicinchoninic acid method. Electrophoresis was performed using $15 \mu \mathrm{g}$ of samples and $10 \%$ SDS-PAGE gels, followed by transfer of the proteins to $0.45 \mathrm{~mm}$ Sequi Blot polyvinylidene fluoride membranes. After they were incubated with $5 \%$ non-fat milk, the membranes were then incubated overnight at $4^{\circ} \mathrm{C}$ with primary antibodies against CaSR (1:1,000; Abcam; cat. no. WH0000846M1) and $\beta$-actin (1:1,000; Wuhan Boster Biological Technology, Ltd; cat. no. A0760-41M). After washing, the membranes were incubated with fluorescence-labelled goat anti-mouse or anti-rabbit IgGs (1:20,000; Wuhan Boster Biological Technology, Ltd; cat. no. ab2891) for $\sim 2 \mathrm{~h}$ at room temperature. Finally, the protein was visualized using an enhanced chemiluminescence system (Pierce; Thermo Fisher Scientific, Inc). The intensities of the protein bands were quantified using Bio-Rad Quantity One 4.6.2 software (Bio-Rad Laboratories, Inc), and the levels of the protein detected were normalized to that of $\beta$-actin.

Preparation of isolated artery rings $(31,32)$. Following sacrifice, the gastrointestinal tract with the mesenteric arcade attached was excised rapidly from rats and steeped in a physiological saline solution (PSS; $119 \mathrm{mmol} / \mathrm{l} \mathrm{NaCl}, 4.69 \mathrm{mmol} / \mathrm{l}$ $\mathrm{KCl}, 1.17 \mathrm{mmol} / 1 \mathrm{MgSO}_{4} \cdot 7 \mathrm{H}_{2} \mathrm{O}, 1.18 \mathrm{mmol} / 1 \mathrm{KH}_{2} \mathrm{PO}_{4}$, $2.5 \mathrm{mmol} / 1 \mathrm{CaCl}_{2}, 25 \mathrm{mmol} / 1 \mathrm{NaHCO}_{3}, 0.026 \mathrm{mmol} / 1 \mathrm{EDTA}$ and $5.5 \mathrm{mmol} / \mathrm{l}$ glucose, which was bubbled with $95 \% \mathrm{O}_{2}$ and $5 \% \mathrm{CO}_{2}$, resulting in a $\mathrm{pH}$ of 7.4 at $4^{\circ} \mathrm{C}$ ) (33). Second-order small mesenteric arteries $(<400 \mu \mathrm{m}$ internal diameter $)$ were dissected and cleaned of adhering fat and connective tissues (34). They were then cut into $2-3 \mathrm{~mm}$ blood vessels; tissues were fixed within $45 \mathrm{~min}$ of sacrifice.

Pressure myograph techniques for detecting blood vessel diameter. The blood vessel segment was placed in a perfusion chamber filled with PSS, connected to a glass microelectrode (diameter: $\sim 50-100 \mu \mathrm{m}$ ), and fixed to prevent air leakage. The perfusion chamber was moved to the microscope stage, with the magnification set as 10 (objective) x10 (eyepiece). During the incubation of the blood vessels, the water bath was continuously permeated with mixed gas $\left(95 \% \mathrm{O}_{2}\right.$ and $5 \% \mathrm{CO}_{2}$ ) and the temperature was maintained at $37^{\circ} \mathrm{C}$. The pressure was increased, and the initial parameter settings were: P1 (20 mmHg), P2 (5 mmHg), and a duration of $3 \mathrm{~min}$. After that, the $\mathrm{P} 2$ pressure was increased to $20 \mathrm{mmHg}$, and the duration was increased to $5 \mathrm{~min}$. Then, the pressure was increased by $10 \mathrm{mmHg}$ for $5 \mathrm{~min}$ each time until it stabilized to $60 \mathrm{mmHg}$. The vascular segments were incubated for $1 \mathrm{~h}$ in a PSS solution maintained at $60 \mathrm{mmHg}, 37^{\circ} \mathrm{C}$, and $\mathrm{pH} 7.4$, and the PSS fluid was changed every $20 \mathrm{~min}$ during the incubation period. The vascular segment was normalized after the equilibration (35), and the potassium physiological saline solution (KPSS, a depolarizing stimulus) fluid was used to detect the activity of the blood vessels. The KPSS contained: $123.70 \mathrm{mmol} / 1 \mathrm{KCl}, 1.17 \mathrm{mmol} / 1 \mathrm{MgSO}_{4} \cdot 7 \mathrm{H}_{2} \mathrm{O}, 1.18 \mathrm{mmol} / 1$ $\mathrm{KH}_{2} \mathrm{PO}_{4}, 2.5 \mathrm{mmol} / 1 \mathrm{CaCl}_{2}, \mathrm{NaHCO}_{2} 25 \mathrm{mmol} / \mathrm{l} \mathrm{NaHCO}$, $0.026 \mathrm{mmol} / 1 \mathrm{EDTA}$, and $5.5 \mathrm{mmol} / 1$ glucose. A vascular contraction amplitude greater than the diameter of $1 / 3$ was

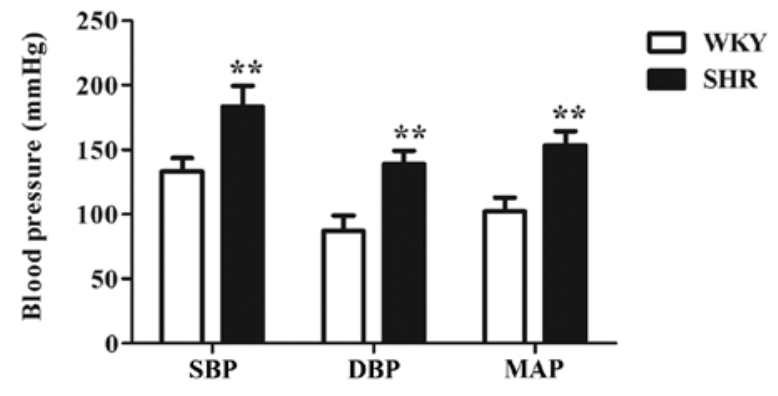

Figure 1. Comparison of blood pressure values between the WKY and SHR. The data are expressed as the mean \pm standard deviation $(n=6) .12$-week-old SHR groups vs. the age-matched WKY groups, ${ }^{* *} \mathrm{P}<0.01$. WKY, Wistar Kyoto rat; SHRs, spontaneously hypertensive rat; SBP, systolic blood pressure; DBP, diastolic blood pressure; MAP, mean arterial pressure.

observed, and contraction after reaching the maximum or smooth platform with Ach $\left(10^{-5} \mathrm{~mol} / \mathrm{l}\right)$ diastolic blood vessels was achieved. The relaxation rate was $>60-80 \%$ with the endothelium-intact, and the vascular activity was good, which could be used in the experiment or discarded.

For denuded endothelium, the vascular tissue was rotated once around the tip of the microelectrode of the glass, or the gas was injected into the vessel segment slowly (36). Indomethacin $\left(10^{-5} \mathrm{~mol} / \mathrm{l}\right)$ and L-NAME $\left(10^{-4} \mathrm{~mol} / \mathrm{l}\right)$ were pre-incubated for

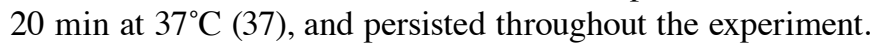
Providing that Ach induced the relaxation of blood vessels by $<5 \%(38,39)$, it was considered that the endothelium was denuded. The experiment commenced after the specimens were rinsed three times with PSS. The PSS solution in the water bath was controlled at $5 \mathrm{ml}$ and using a micropipette, $10^{-7}, 10^{-6}, 10^{-5}$, $10^{-4}, 10^{-3}$ or $10^{-2} \mathrm{~mol} / 1 \mathrm{PE}$ (GPCR-mediated), Ach (endothelium-dependent vasodilator) and SNP (endothelium-independent vasodilator), were respectively added. After the vascular response reached a maximum or stable state, a higher concentration was added. The final concentration was $10^{-9}-10^{-4} \mathrm{~mol} / \mathrm{l}$, and the effect of the drug on the blood vessel diameter was observed. The effects of inhibitors (NPS2143, $10^{-5} \mathrm{~mol} / \mathrm{l}$; U73122, $10^{-5} \mathrm{~mol} / \mathrm{l}$; 2-APB, $10^{-4} \mathrm{~mol} / \mathrm{l}$; MDL12330A, $10^{-5} \mathrm{~mol} / \mathrm{l}$; CAP, $10^{-4} \mathrm{~mol} / \mathrm{l}$; LOS, $\left.10^{-4} \mathrm{~mol} / \mathrm{l}\right)$ on the blood vessel diameter were observed. The inhibitors were pre-incubated for $20 \mathrm{~min}$ at $37^{\circ} \mathrm{C}$, and the inhibitors persisted throughout the experiment (CaSR agonist and an inhibitor group given calcium-free PSS and KPSS). Then, different concentrations of PE, Ach, and SNP $\left(10^{-9}-10^{-4} \mathrm{~mol} / \mathrm{l}\right)$ were cumulatively added to observe the effects of the drug on the blood vessel diameter. Myoview software (110P; Danish Myo Technology A/S) was used to control the intravascular pressure and to record the experimental data.

The vascular diameter change (D) was calculated by the following formula: $\mathrm{D}(\mu \mathrm{m})=\mathrm{Dp}-\mathrm{Dx}$, where $\mathrm{Dp}$ is the diameter of the vascular segment of the PSS fluid when it is stable, Dx is the diameter after vasoconstriction following the administration of different concentrations of the drug, Dp' is the diameter of vasodilation after the administration of different concentrations of drugs, and Dx' is the blood vessel diameter after pre-contraction. Vasoconstriction rate $(\%)=(\mathrm{Dp}-\mathrm{Dx}) / \mathrm{Dx}$ $\mathrm{x} 100 \%$. Vasodilation rate $(\%)=\left(\mathrm{Dp}^{\prime}-\mathrm{Dx} \mathrm{x}^{\prime}\right) / \mathrm{Dx}^{\prime} \mathrm{x} 100 \%$.

Statistical analysis. The experimental data are expressed as the mean \pm standard deviation. For comparisons between the 
A

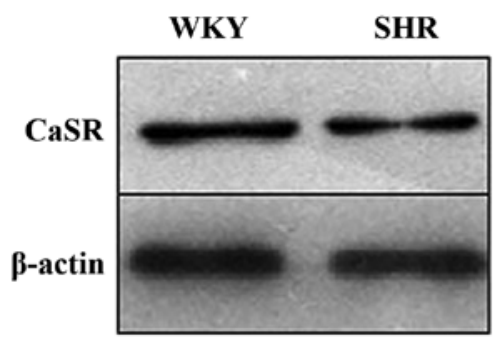

B

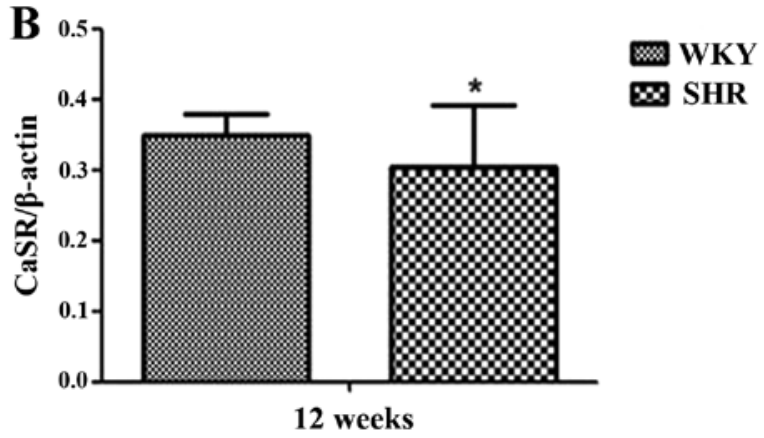

Figure 2. CaSR protein expression in the mesenteric artery of the WKY and SHR groups. (A) Western blot analysis and (B) densitometric analysis. The data are expressed as the mean \pm standard deviation $(n=7)$. WKY groups vs. SHR groups, ${ }^{*} \mathrm{P}<0.05$. WKY, Wistar Kyoto rats; SHR, spontaneously hypertensive rats; CaSR, calcium-sensing receptor.

two groups, a Student's t-test or the rank sum test was used. Between multiple sample means, one-way analysis of variance followed Dunnett's post-hoc test or variance for non-parametric tests was used. The analysis was performed with SPSS 19.0 software, in which a bilateral $\mathrm{P}<0.05$ was considered to indicate a statistically significant difference. GraphPad Prism 5.0 was used calculate the inhibitory concentration to exhibit $50 \%$ of the maximum contraction and diastolic effect $\left(\mathrm{IC}_{50}\right)$ and the maximum contraction or diastolic amplitude $\left(\mathrm{E}_{\max }\right)$ values as non-linear regression curve fits.

\section{Results}

BP of SHRs is significantly higher than that of the WKY group. The arterial BP of the rats was measured by the tail cuff method. The results showed that the BP values (SBP, DBP and MAP) of the SHR group were significantly higher than those of WKY group of the same age $(\mathrm{P}<0.01$; Fig. 1$)$.

CaSR protein expression in the MA of the WKY and SHR. Western blotting was used to analyze the expression of the CaSR protein in the MA of the rats. The results showed that the CaSR protein was expressed in the MA of the WKY and SHR. Compared with that of the WKY group, CaSR total protein expression in the SHR group was significantly reduced $(\mathrm{P}<0.05$; Fig. 2$)$.

Effects of various drugs on vascular tension of the MA of isolated rats

Vasoconstriction of the SHR group was higher, while vasodilation was lower than that of the WKY group, which were endothelium-independent effects. PE-induced contraction and Ach/SNP-induced vasodilation in the MA of the rats were measured by the pressure myograph technique. The results showed that: $\mathrm{PE}$ induced vasoconstriction of the rat MA in a dose-dependent manner (Table I; Fig. 3A), while Ach induced vasodilation (Table I; Fig. 3E). Compared with that of the WKY group, the maximal contraction response of the PE-induced SHR was significantly increased $\left(\mathrm{E}_{\max }\right.$ values: $34.78 \pm 0.90$ vs. $45.32 \pm 1.41 \%$, respectively; $\mathrm{P}<0.05 ; \mathrm{n}=6$ ). The $\mathrm{IC}_{50}$ values were $0.44 \pm 0.14$ and $0.33 \pm 0.14$, respectively. The maximal relaxation response of the Ach-induced SHR group was significantly reduced ( $\mathrm{E}_{\max }$ values: $65.2 \pm 4.03$ vs. $53.41 \pm 11.91 \%$, respectively; $\mathrm{P}<0.01 ; \mathrm{n}=6)$. The $\mathrm{IC}_{50}$ values were $-1.32 \pm 0.20$ and $0.03 \pm 0.88$, respectively.
Table I. Effect of pretreatment with the calcium sensing receptor inhibitor NPS2143 on vasoconstriction and relaxation reactivity.

\begin{tabular}{llcr}
\hline Rat & \multicolumn{1}{c}{ Group } & Emax $(\%)$ & \multicolumn{1}{c}{$\mathrm{IC}_{50}(\mu \mathrm{M})$} \\
\hline WKY & PE & $34.78 \pm 0.90$ & $0.44 \pm 0.14$ \\
& PE-E & $38.98 \pm 1.12$ & $-0.13 \pm 0.05$ \\
& PE + NPS2143 & $11.67 \pm 0.75$ & $0.02 \pm 0.14$ \\
& PE + NPS2143-E & $41.53 \pm 1.34$ & $0.60 \pm 0.06$ \\
& Ach & $65.2 \pm 4.03$ & $-1.32 \pm 0.20$ \\
& SNP & $40.24 \pm 11.26$ & $1.68 \pm 0.73$ \\
& Ach + NPS2143 & $25.74 \pm 3.81$ & $-1.37 \pm 0.14$ \\
SHR & SNP + NPS2143 & $41.16 \pm 1.19$ & $-1.46 \pm 0.11$ \\
& PE & $45.32 \pm 1.41^{\mathrm{a}}$ & $0.33 \pm 0.14$ \\
& PE-E & $49.81 \pm 1.33^{\mathrm{b}}$ & $-0.23 \pm 0.04$ \\
& PE + NPS2143 & $35.25 \pm 1.28^{\mathrm{c}}$ & $0.46 \pm 0.05$ \\
& PE + NPS2143-E & $50.64 \pm 0.76^{\mathrm{d}}$ & $-0.03 \pm 0.05$ \\
& Ach & $53.41 \pm 11.91^{\mathrm{e}}$ & $0.03 \pm 0.88$ \\
& SNP & $47.50 \pm 0.47^{\mathrm{f}}$ & $-0.85 \pm 0.05$ \\
& Ach + NPS2143 & $48.98 \pm 5.96^{\mathrm{g}}$ & $-1.27 \pm 0.18$ \\
& SNP + NPS2143 & $53.66 \pm 1.10^{\mathrm{h}}$ & $-1.51 \pm 0.11$ \\
\hline
\end{tabular}

The data are expressed as the mean \pm standard deviation $(n=6)$. WKY PE vs. SHR PE groups, ${ }^{\mathrm{a}} \mathrm{P}<0.01$; WKY PE-E groups vs. SHR PE-E groups, ${ }^{b} \mathrm{P}<0.05$; WKY $\mathrm{PE}+\mathrm{NPS} 2143$ groups vs. SHR $\mathrm{PE}+\mathrm{NPS} 2143$ groups, ${ }^{\mathrm{C}} \mathrm{P}<0.01$; WKY $\mathrm{PE}+\mathrm{NPS} 2143-\mathrm{E}$ groups vs. SHR PE+NPS2143-E groups, ${ }^{d} \mathrm{P}<0.05$; WKY Ach groups vs. SHR Ach groups, ${ }^{e} \mathrm{P}<0.01$; WKY SNP vs. SHR SNP groups, ${ }^{\mathrm{P}}<0.01$; WKY Ach+NPS2143 groups vs. SHR Ach+NPS2143 groups, ${ }^{g} \mathrm{P}<0.05$; WKY SNP+NPS2143 groups vs. SHR SNP+NPS2143 groups, ${ }^{\mathrm{h}} \mathrm{P}<0.01$. -E, endothelial removal; $\mathrm{IC}_{50}$, inhibitory concentration to exhibit $50 \%$ of the maximum contraction and diastolic effect; WKY, Wistar Kyoto rats; SHR, spontaneously hypertensive rats; PE, phenylephrine; Ach, acetylcholine; SNP, sodium nitroprusside, NPS2143, calcium sensing receptor inhibitor.

In the endothelium-denuded group, PE induced vasoconstriction (Table I; Fig. 3B-D), while SNP-induced vasodilation of the rat MA in a dose-dependent manner (Table I; Fig. 3F). The PE-induced WKY and SHR groups exhibited significantly increased vasoconstriction amplitudes; compared with the corresponding WKY group, PE-induced endothelium-denuded 
A

PE

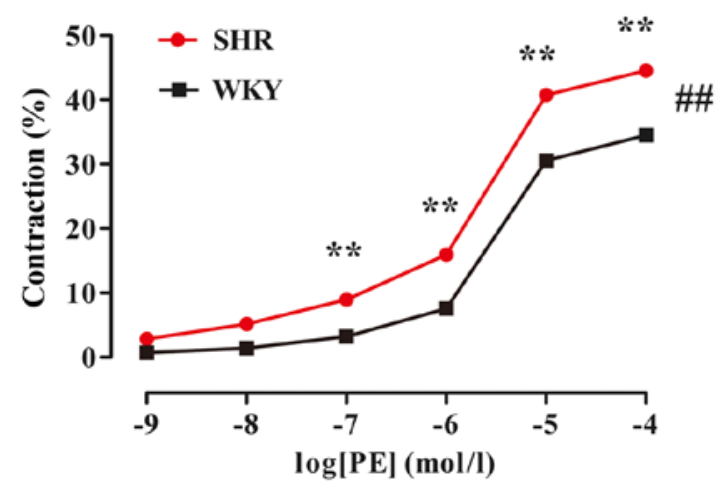

C

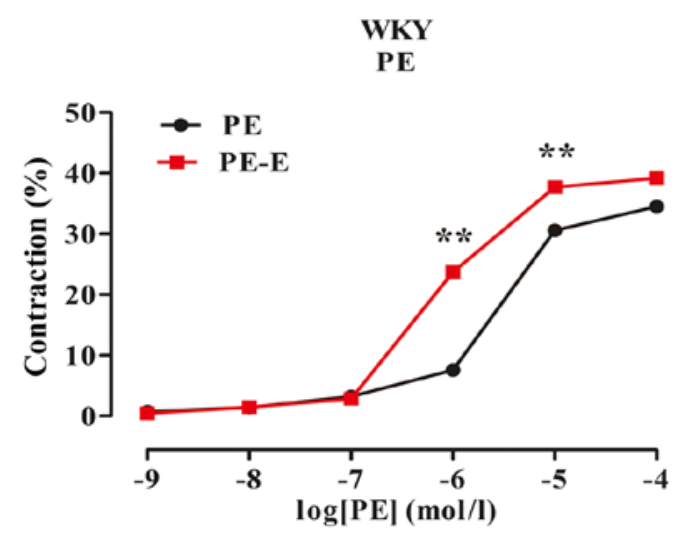

E

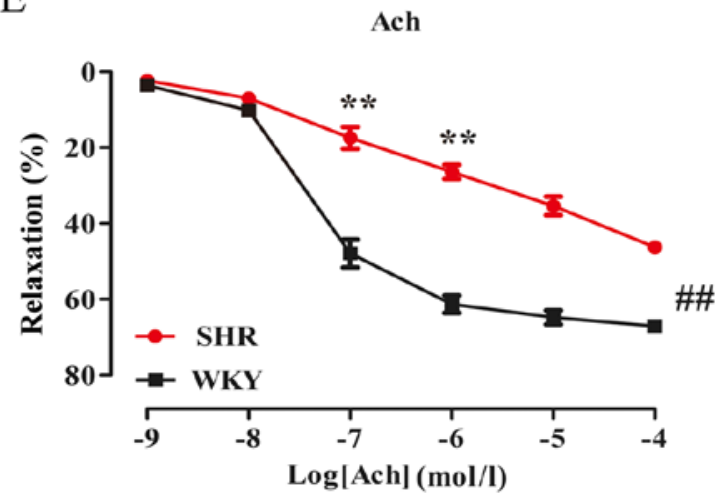

B

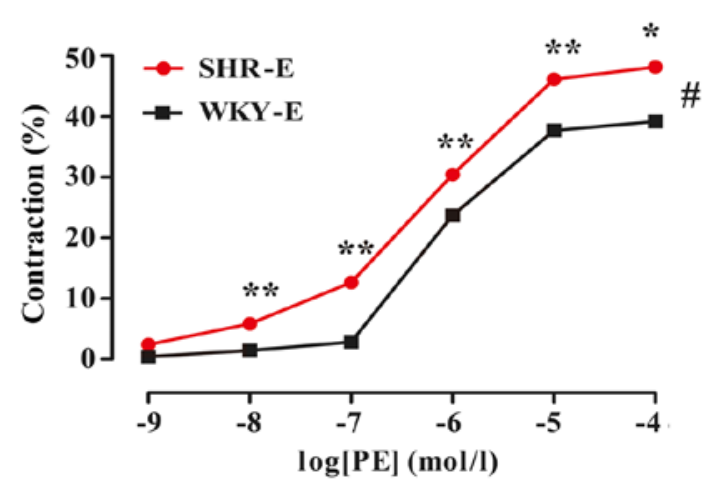

D

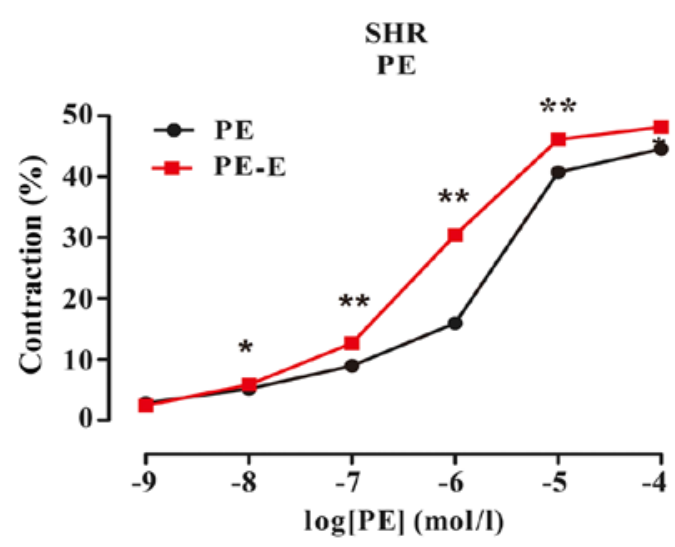

F

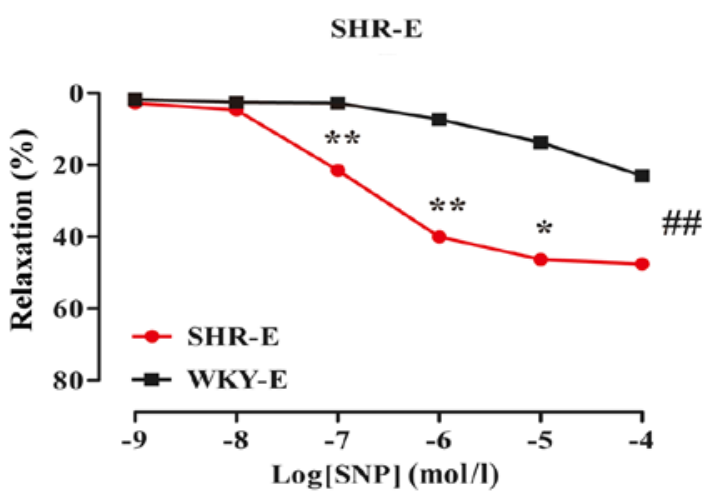

Figure 3. Comparison of the contractions and diastolic amplitudes of the mesenteric artery in the WKY and SHR groups. The data are expressed as the mean \pm standard deviation (n=6). (A) SHR PE vs. WKY PE groups, ${ }^{\# \#} \mathrm{P}<0.01$; (B) SHR PE-E groups vs. WKY PE-E groups, ${ }^{\#} \mathrm{P}<0.05$. (C) WKY PE groups vs. WKY PE-E groups, $P>0.05$. (D) SHR PE groups vs. SHR PE-E groups, $P>0.05$. (E) SHR Ach groups vs. WKY Ach groups, "\# $\mathrm{P}<0.01 ;(\mathrm{F}) \mathrm{WKY}$ SNP vs. SHR SNP groups, ${ }^{\# \#} \mathrm{P}<0.01 .{ }^{*} \mathrm{P}<0.05,{ }^{* *} \mathrm{P}<0.01$, vs. the adjacent concentrations in each group. -E, endothelial removal; WKY, Wistar Kyoto rats; SHR, spontaneously hypertensive rats; PE, phenylephrine; Ach, acetylcholine; SNP, sodium nitroprusside.

SHRs had a maximal contractile response that was significantly increased ( $\mathrm{E}_{\max }$ values: $38.98 \pm 1.12$ vs. $49.81 \pm 1.33 \%$, respectively; $\mathrm{P}<0.05 ; \mathrm{n}=6)$. The $\mathrm{IC}_{50}$ values were $-0.13 \pm 0.05$ and $-0.23 \pm 0.04$, respectively. The SNP-induced maximum relaxation response in the SHR group was greater than that in the WKY group $\left(\mathrm{E}_{\max }\right.$ values: $40.24 \pm 11.26$ vs. $47.50 \pm 0.47 \%$, respectively; $\mathrm{P}<0.01 ; \mathrm{n}=6$ ). $\mathrm{The} \mathrm{IC}_{50}$ values were $1.68 \pm 0.73$ and $-0.85 \pm 0.05$, respectively.

NPS2143 and NPSR568 reduce vasoconstriction, and promote vasodilation in MA, which is partially endothelium-dependent. The effects of the NPS2143 and NPSR568 on the vascular tone in rats were investigated. The results showed that: NPS2143 $\left(10^{-8}-10^{-5} \mathrm{~mol} / \mathrm{l}\right)$ caused contraction of the rat MA (Fig. 4A). When the concentration of NPS2143 was $10^{-5} \mathrm{~mol} / \mathrm{l}$, a significant contraction amplitude of the MA in rats was observed $(\mathrm{P}<0.01)$; the contraction amplitude of the WKY group was markedly greater than that of the SHR group $(\mathrm{P}>0.05)$. NPSR568 $\left(10^{-8}-10^{-5} \mathrm{~mol} / \mathrm{l}\right)$ induced vasodilation of the MA in the SHR group in a dose-dependent manner (Fig. 4B), and the diastolic amplitude of the endothelium-intact group was significantly greater than that of the endothelium-denuded group $(\mathrm{P}<0.01)$. Different concentrations of NPSR568 were pre-incubated for $20 \mathrm{~min}$ with MA samples to study the effect of PE, Ach, and SNP on vascular tone (Fig. 4C-F). For the 
A

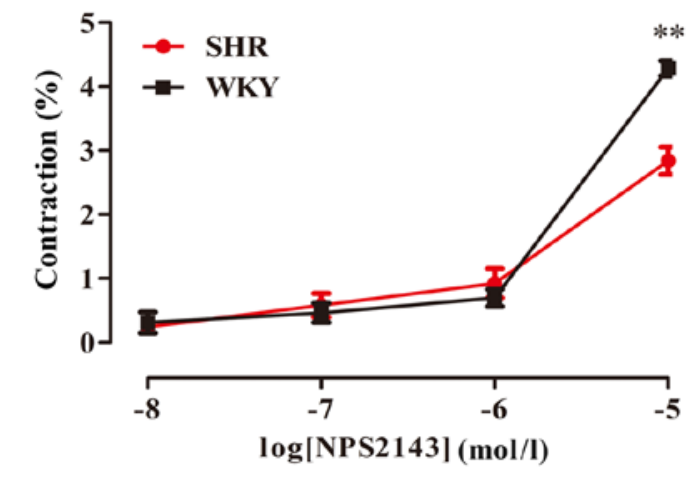

C

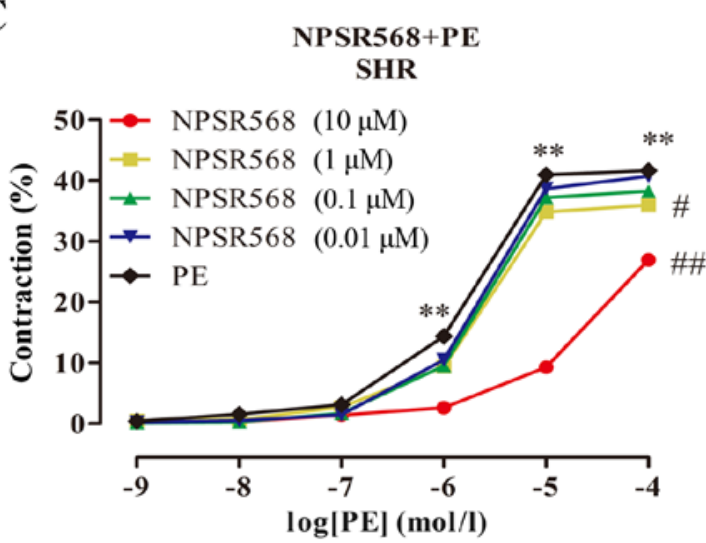

$\mathrm{E}$

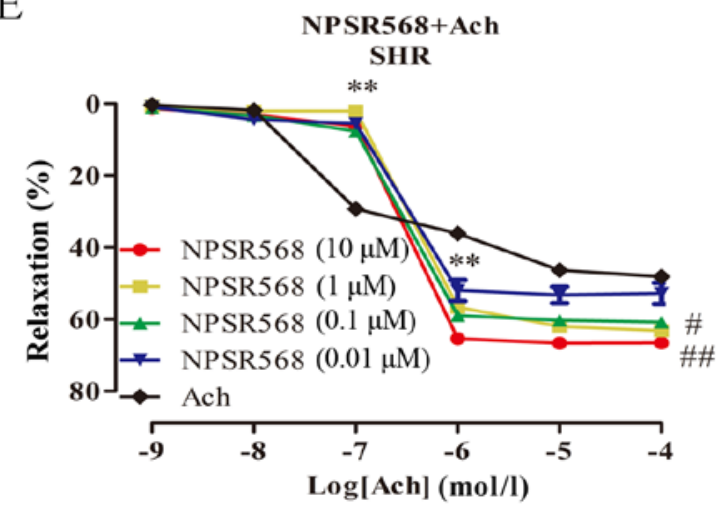

B

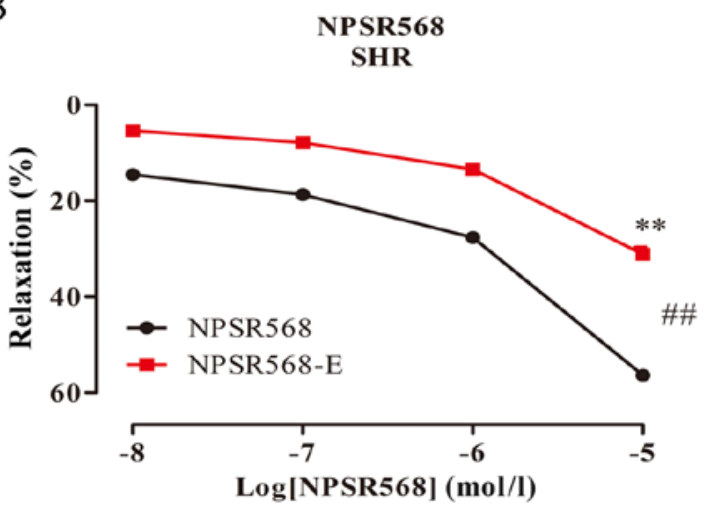

$\mathrm{D}$

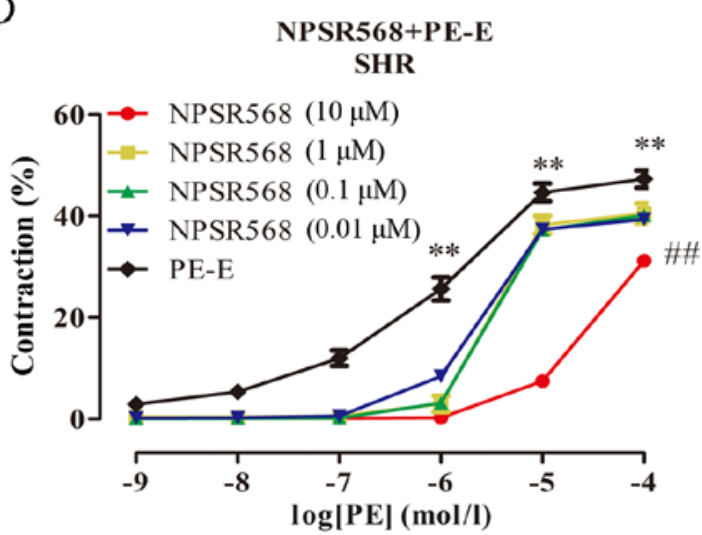

F

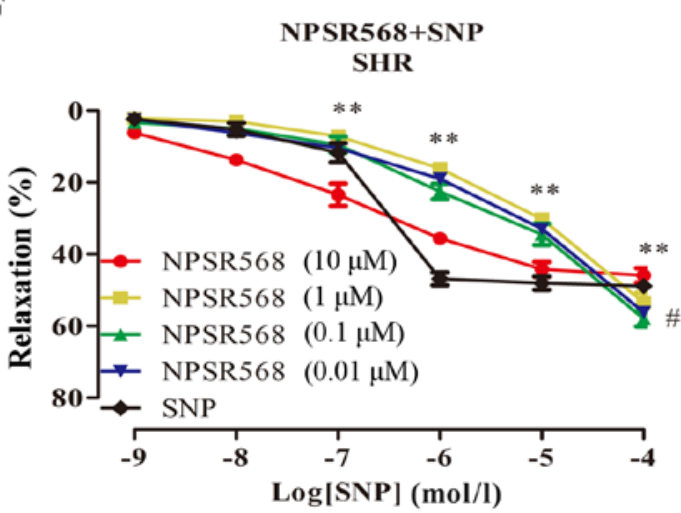

Figure 4. Effect of NPSR568 on vascular reactivity. The data are expressed as the mean \pm standard deviation (n=6). (A) WKY NPS2143 groups vs. SHR NPS2143 groups, P >0.05; (B) WKY NPSR568 groups vs. SHR NPSR568 groups, ${ }^{\# \#} \mathrm{P}<0.01$; (C) SHR PE groups vs. SHR PE + NPSR568 $(1 \mu \mathrm{M})$ groups, ${ }^{\#} \mathrm{P}<0.05 ;{ }^{\# \#} \mathrm{P}<0.01$, vs. SHR PE + NPSR568 $(10 \mu \mathrm{M})$ group. (D) SHR PE + NPSR568-E $(10 \mu \mathrm{M})$ groups vs. SHR PE-E groups, ${ }^{\# \# P} \mathrm{P}<0.01 ;$; (E) SHR Ach group vs. SHR Ach + NPSR568 $(1 \mu \mathrm{M})$ group, ${ }^{\# P}<0.05 ;{ }^{\# /} \mathrm{P}<0.01$, vs. SHR Ach + NPSR568 $(10 \mu \mathrm{M})$ groups. (F) SHR SNP group vs. SHR SNP + NPSR568 (10 $\left.\mu \mathrm{M}\right)$ group, ${ }^{~} \mathrm{P}<0.05 .{ }^{*} \mathrm{P}<0.05,{ }^{* *} \mathrm{P}<0.01$, vs. the adjacent concentrations in each group. -E, endothelial removal; WKY, Wistar Kyoto rats; SHR, spontaneously hypertensive rats; PE, phenylephrine; Ach, acetylcholine; SNP, sodium nitroprusside; NPSR568, CaSR agonists.

endothelium-intact group, when the concentration of NPSR568 was $10^{-5} \mathrm{~mol} / \mathrm{l}$, PE-induced contractions were significantly inhibited $(\mathrm{P}<0.01)$, and the vasodilatory amplitude was the most significantly increased $(\mathrm{P}<0.01$; Fig. 4B). After the endothelium was denuded, a similar vascular reactivity was exhibited.

NPS2143 reduces vasoconstriction and enhances vasodilation in MA, which is partly endothelium-dependent. The effects of NPS2143 on the contraction and vasodilation of the MA in rats was investigated. The results showed that after pre-incubation of MA with NPS2143 $\left(10^{-5} \mathrm{~mol} / \mathrm{l}\right)$ for $20 \mathrm{~min}$, PE-induced vasoconstriction of the rat MA occurred in a dose-dependent manner (Table I; Fig. 5A-C). Ach also induced a relaxatory response of the rat MA in a dose-dependent manner (Table I; Fig. 5G-I). The inhibitory effect of NPS2143 on the PE-WKY group was greater than that of the PE-SHR group $\left(\mathrm{E}_{\max }\right.$ values: $11.67 \pm 0.75$ vs. $35.25 \pm 1.28 \%$, respectively; $\mathrm{P}<0.01 ; \mathrm{n}=6)$. The $\mathrm{IC}_{50}$ values were $0.02 \pm 0.14$ and $0.46 \pm 0.05$, respectively, while the maximum diastolic amplitude of Ach + NPS2143-induced WKY was lower than that of the SHR ( $E_{\max }$ values: $25.74 \pm 3.81$ vs. $48.98 \pm 5.96 \%$, respectively; $\mathrm{P}<0.05 ; \mathrm{n}=6)$. The $\mathrm{IC}_{50}$ values 
A

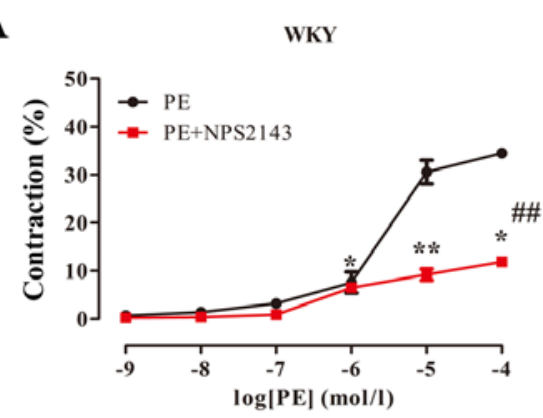

D

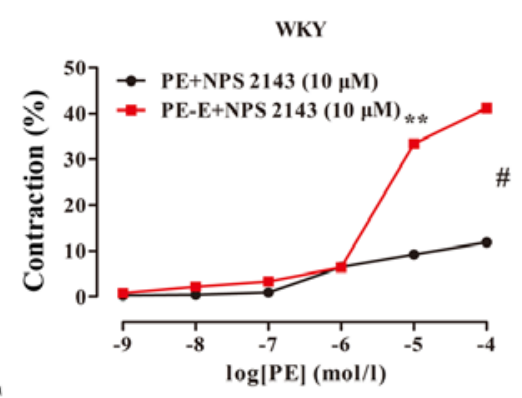

G

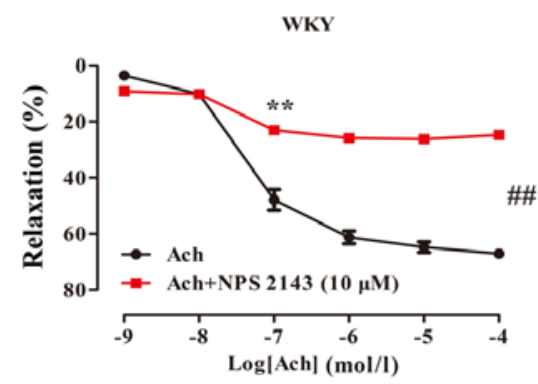

J

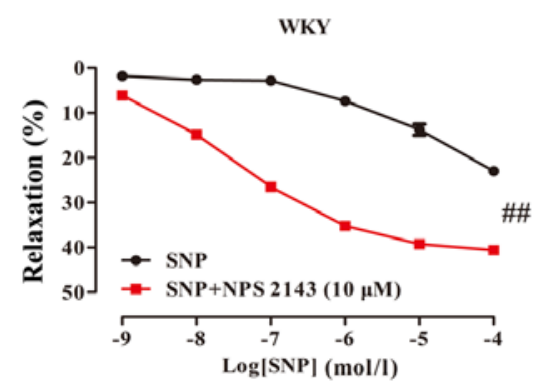

B

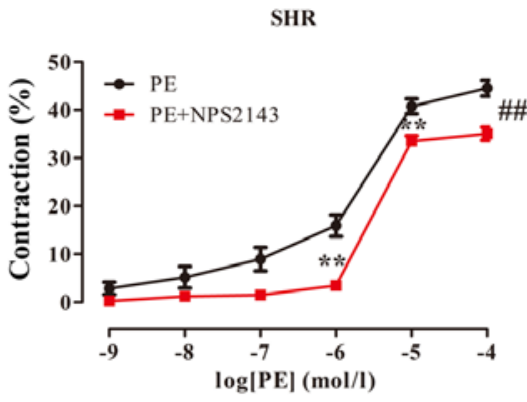

E

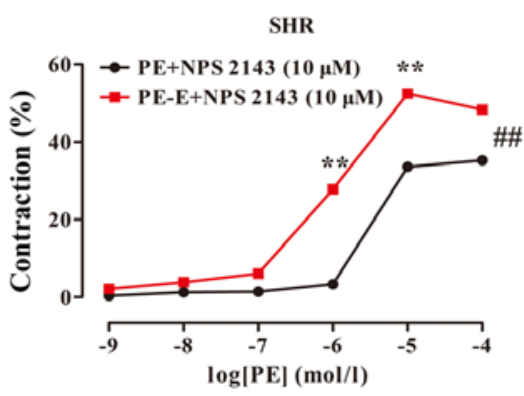

$\mathrm{H}$

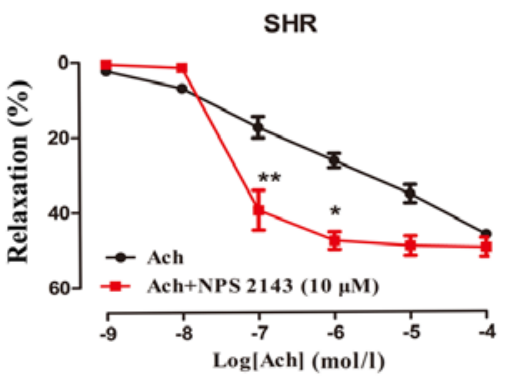

K

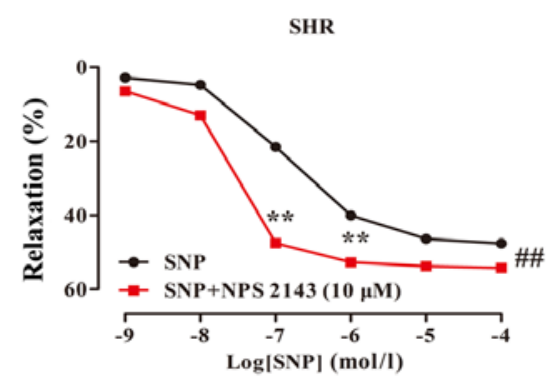

C PE+NPS2143 $(10 \mu M)$

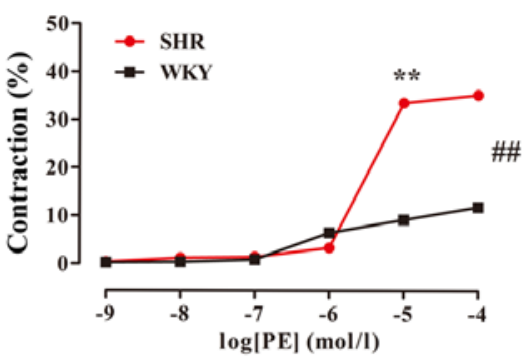

F

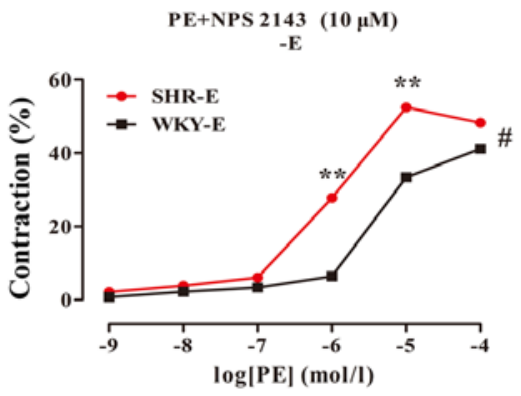

I

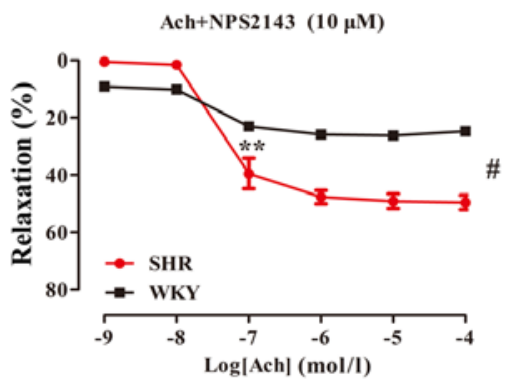

L

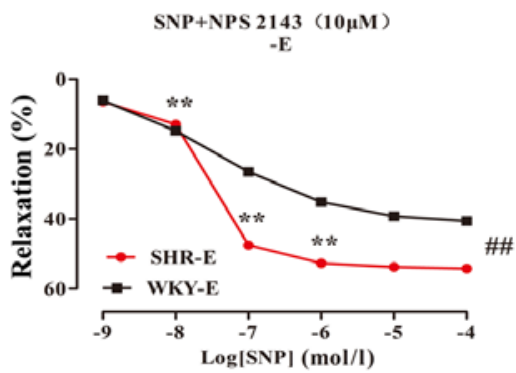

Figure 5. Effect of the CaSR inhibitor NPS2143 on vascular reactivity of the mesenteric artery in the WKY and SHR. The data are expressed as the mean \pm standard deviation (n=6). (A) WKY PE + NPS2143 groups vs. WKY PE groups, ${ }^{\# \#} \mathrm{P}<0.01$; (B) SHR PE groups vs. SHR PE + NPS2143 groups, ${ }^{\# \#} \mathrm{P}<0.01$; (C) WKY PE + NPS2143 groups vs. SHR PE + NPS2143 groups, ${ }^{\# \#}$ P $<0.01$; (D) WKY PE + NPS2143 groups vs. WKY PE + NPS2143-E groups, ${ }^{\#} \mathrm{P}<0.05 ;$ (E) SHR PE + NPS2143 groups vs. SHR PE + NPS2143-E groups, ${ }^{\# \#} \mathrm{P}<0.01$; (F) WKY PE + NPS2143-E groups vs. SHR PE + NPS2143-E groups, ${ }^{\# P}<0.05$; (G) WKY Ach groups vs. WKY Ach + NPS2143 groups, ${ }^{\# \#} \mathrm{P}<0.01 ;(\mathrm{H})$ SHR Ach groups vs. SHR Ach + NPS2143 groups, ${ }^{\# \#} \mathrm{P}<0.01 ;$ (I) WKY Ach + NPS2143 groups vs. SHR Ach + NPS2143 groups, ${ }^{\#} \mathrm{P}<0.05$; (J) WKY SNP groups vs. WKY SNP + NPS2143 groups, ${ }^{\# \#} \mathrm{P}<0.01$; (K) SHR SNP groups vs. SHR SNP+NPS2143 groups, ${ }^{\# \#} \mathrm{P}<0.01 ;(\mathrm{L}) \mathrm{WKY}$ SNP + NPS2143 groups vs. SHR SNP + NPS2143 groups, ${ }^{\# \#} \mathrm{P}<0.01 .{ }^{*} \mathrm{P}<0.05,{ }^{, *} \mathrm{P}<0.01$, vs. the adjacent concentrations in each group. - E, endothelial removal; WKY, Wistar Kyoto rats; SHR, spontaneously hypertensive rats; PE, phenylephrine; Ach, acetylcholine; SNP, sodium nitroprusside; NPS2143, CaSR inhibitor.

were $-1.37 \pm 0.14$ and $-1.27 \pm 0.18$, respectively. Compared with $\mathrm{PE}$ alone, the maximal contraction response with $\mathrm{PE}+$ NPS2143 treatment of the WKY and SHR were significantly reduced ( $\mathrm{E}_{\max }$ values: $34.78 \pm 0.90$ vs. $11.67 \pm 0.75 \% ; 45.32 \pm 1.41$ vs. $35.25 \pm 1.28$ respectively; $\mathrm{P}<0.01 ; \mathrm{n}=6$ ). After NPS2143 treatment, compared with Ach group, the diastolic amplitude of the WKY decreased ( $\mathrm{E}_{\max }$ values: $65.2 \pm 4.03$ vs. $25.74 \pm 3.81 \%$, respectively; $\mathrm{P}<0.01 ; \mathrm{n}=6)$. The $\mathrm{IC}_{50}$ values were $-1.32 \pm 0.20$ and $-1.37 \pm 0.14$, respectively. Compared with Ach group, the diastolic amplitude of the Ach + NPS2143 SHR increased ( $\mathrm{E}_{\max }$ values: $53.41 \pm 11.91$ vs. $48.98 \pm 5.96 \%$, respectively; $\mathrm{P}>0.05 ; \mathrm{n}=6)$. The $\mathrm{IC}_{50}$ values were $0.03 \pm 0.88$ and $-1.27 \pm 0.18$, respectively.

In the endothelium-denuded group, PE induced vasoconstriction in the rat MA in a dose-dependent manner (Table I; Fig. 5D-F). SNP induced vasodilation in the rat MA in a dose-dependent manner (Table I; Fig. 5J-L). The inhibitory effect of NPS2143 on the PE-induced WKY was greater than 
that of the SHR ( $\mathrm{E}_{\max }$ values: $41.53 \pm 1.34$ vs. $50.64 \pm 0.76 \%$, respectively; $\mathrm{P}<0.05 ; \mathrm{n}=6$ ). The $\mathrm{IC}_{50}$ values were $0.60 \pm 0.06$ and $-0.03 \pm 0.05$, respectively. The maximal contraction response of PE + NPS2143 denuded WKY was greater than that of the endothelium-intact group $\left(\mathrm{E}_{\max }\right.$ values: $41.53 \pm 1.34$ vs. $11.67 \pm 0.75 \%$, respectively; $\mathrm{P}<0.05 ; \mathrm{n}=6)$. The $\mathrm{IC}_{50}$ values were $0.60 \pm 0.06$ and $0.02 \pm 0.14$, respectively. The maximum contraction response of PE + NPS2143 denuded SHR was significantly greater than that of the endothelial-intact group ( $\mathrm{E}_{\max }$ values: $50.64 \pm 0.76$ vs. $35.25 \pm 1.28 \%$, respectively; $\mathrm{P}<0.01 ; \mathrm{n}=6)$. The $\mathrm{IC}_{50}$ values were $-0.03 \pm 0.05$ and $0.46 \pm 0.05$, respectively. After the NPS2143 treatment, the SNP-induced increase in the vasodilation in the SHR was greater than that in the WKY ( $\mathrm{E}_{\max }$ values: $41.16 \pm 1.19$ vs. $53.66 \pm 1.10 \%$; $\mathrm{P}<0.01 ; \mathrm{n}=6)$. The $\mathrm{IC}_{50}$ values were $-1.46 \pm 0.11$ and $-1.51 \pm 0.11$, respectively. Compared with the SNP group, SNP + NPS2143 induced a maximal relaxation response in the WKY and SHR ( $\mathrm{E}_{\max }$ values: $40.24 \pm 11.26$ vs. $41.16 \pm 1.19 \%$; $47.50 \pm 0.47$ vs. $53.66 \pm 1.10 \%$, respectively; $\mathrm{P}<0.01 ; \mathrm{n}=6$ ).

$P L C-I P_{3} / A C-V / c A M P / R A S$ pathway inhibitors reduce vasoconstriction and increase vasodilation in the MA, which is partially endothelium-dependent. The effect of inhibitors on the vasoconstriction and vasodilation of the MA in rats was investigated in which $\mathrm{PLC}-\mathrm{IP}_{3} / \mathrm{AC}-\mathrm{V} / \mathrm{cAMP} / \mathrm{RAS}$ pathway inhibitors were separately administered. After the MA was pre-incubated for $20 \mathrm{~min}$, PE induced vasoconstriction in the rat MA in a dose-dependent manner (Table II; Fig. 6A and B). Ach concentration-dependently induced vasodilation in the rat MA (Table II; Fig. 6E and F). Compared with the PE group, the vasoconstriction amplitude in response to the inhibitors showed an overall weakening trend; the contraction amplitude with $10^{-5} \mathrm{~mol} / 1 \mathrm{PE}$ was notably weakened. Therefore, a subsequent vasodilation function test was performed in which PE $\left(10^{-3} \mathrm{~mol} / \mathrm{l}\right)$ was selected to pre-constrict blood vessels. U73122, 2-APB, MDL12330A, CAP and LOS acted on the blood vessels. Compared with the PE group, the maximal contractile responses of the PE + inhibitors WKY and SHR were significantly lower (Table I; WKY $\mathrm{E}_{\max }$ values: $34.78 \pm 0.90$ vs. $30.86 \pm 1.70,24.05 \pm 2.25,20.66 \pm 2.95$, $30.08 \pm 3.46,30.49 \pm 1.44 \%$; SHR $\mathrm{E}_{\max }$ values: $45.32 \pm 1.41 \mathrm{vs}$. $36.65 \pm 0.51,12.18 \pm 2.92,11.89 \pm 1.44,31.36 \pm 2.42,31.01 \pm 1.99 \%$, respectively; $\mathrm{P}<0.01 ; \mathrm{n}=6$ ). Compared with the Ach group, the maximal vasodilatory responses of the Ach + inhibitors WKY and SHR were significantly increased (WKY $\mathrm{E}_{\max }$ values: $65.2 \pm 4.03$ vs. $61.12 \pm 1.64,63.69 \pm 1.04,73.14 \pm 4.41$, $67.68 \pm 6.15,58.22 \pm 0.90 \%$; SHR $\mathrm{E}_{\max }$ values: $53.41 \pm 11.91 \mathrm{vs}$. $67.48 \pm 3.43,66.12 \pm 8.76,57.97 \pm 5.82,50.70 \pm 3.67,52.70 \pm 1.78 \%$, respectively; $\mathrm{P}<0.01 ; \mathrm{n}=6$ ). However, in the SHR, U73122 and 2-APB appeared to elicit contractile reactivity when the Ach concentration was $10^{-6}$ and $10^{-5} \mathrm{~mol} / 1$, respectively.

In the endothelium-denuded group, PE induced vasoconstriction of the rat MA in a dose-dependent manner (Table II; Fig. 6C and D); SNP induced vasodilation in the rat MA in a similar manner (Table II; Fig. 6G and H). After the signalling pathway inhibitors acted on the endothelium-denuded blood vessels, the maximal vasoconstriction responses of the PE-induced WKY and SHR were significantly reduced (Table I; WKY $\mathrm{E}_{\max }$ values: $38.98 \pm 1.12$ vs. $39.98 \pm 0.92$, $53.29 \pm 1.68,41.26 \pm 1.20,33.25 \pm 2.18,39.85 \pm 2.29 \%$; SHR $\mathrm{E}_{\max }$ values: $49.81 \pm 1.33$ vs. $36.41 \pm 3.02,25.48 \pm 1.80,38.12 \pm 0.97$, $33.46 \pm 2.12,38.35 \pm 0.73 \%$, respectively; $\mathrm{P}<0.01 ; \mathrm{n}=6$ ). Compared with the endothelial-denuded PE group, and the attenuation was smaller than that of the endothelium-intact group (Table II). After the signalling pathway inhibitors acted on the blood vessels, maximal vasodilator responses of the SNP-induced WKY were significantly increased $\left(\mathrm{E}_{\max }\right.$ values: $40.24 \pm 11.26$ vs. $18.57 \pm 18.57,45.85 \pm 4.13,33.17 \pm 0.97$, $35.90 \pm 16.53,34.62 \pm 6.52 \%$, respectively; $\mathrm{P}<0.01 ; \mathrm{n}=6)$. The vasodilation of the SHR following U73122 and 2-APB treatment was significantly increased compared with SNP alone ( $E_{\max }$ values: $47.50 \pm 0.47$ vs. $49.27 \pm 0.76,30.67 \pm 3.92 \%$, respectively; $\mathrm{P}<0.05 ; \mathrm{n}=6$ ), and the diastolic response of the other inhibitor groups markedly changed $(\mathrm{P}>0.05)$. The diastolic amplitude induced by SNP in the endothelium-denuded WKY and SHR was lower than that in the endothelium-intact group (Table II).

CaSR inhibitors combined with PLC-IP $/ A C$-V/cAMP/RAS pathway inhibitors significantly decrease vasoconstriction and enhance vasodilation in the MA of the rats. The effects of CaSR inhibitors and various signalling pathways inhibitors on the vasoconstriction and vasodilation of MA in rats were investigated. CaSR inhibitors were pre-incubated with PLC-IP $/$ /AC-V/cAMP/RAS pathway inhibitors for $20 \mathrm{~min}$. The results revealed that $\mathrm{PE}$ and Ach concentration-dependently induced vasoconstriction and vasodilation in the rat MA in the presence of NPS2143, respectively (Table III; Fig. 7A-D). Compared with the PE + NPS2143 group, PE induced a significant reduction in the maximal contractile responses in the WKY and SHR (Tables I and III; WKY $\mathrm{E}_{\max }$ values: $11.67 \pm 0.75$ vs. $4.01 \pm 0.86,6.14 \pm 4.59,4.06 \pm 1.27,3.19 \pm 0.64,3.33 \pm 0.54 \%$; SHR $\mathrm{E}_{\max }$ values: $35.25 \pm 1.28$ vs. $24.42 \pm 2.21,5.53 \pm 2.76,4.22 \pm 3.12$, $5.06 \pm 2.36,7.90 \pm 5.79 \%$, respectively; $\mathrm{P}<0.01 ; \mathrm{n}=6$ ), and some blood vessels no longer exhibited contractile responses. Compared with that of the Ach + NPS2143 group, the maximal vasodilator response of the WKY and SHR induced by Ach was significantly increased (WKY $\mathrm{E}_{\max }$ values: $25.74 \pm 3.81$ vs. $25.59 \pm 2.86,28.02 \pm 3.02,27.07 \pm 2.80,21.63 \pm 1.83,25.04 \pm 0.62 \%$; SHR $\mathrm{E}_{\max }$ values: $48.98 \pm 5.96$ vs. $59.25 \pm 8.86,67.29 \pm 7.48$, $60.76 \pm 8.35,51.17 \pm 0.65,54.57 \pm 3.22 \%$, respectively; $\mathrm{P}<0.01$; $\mathrm{n}=6$ ), and a complete vasodilatory response was induced by Ach at low concentrations (Table III and Fig. 7C-D).

\section{Discussion}

Hypertension has long been considered a leading cause of cardiovascular morbidity and mortality (40). Despite the fact that there are effective antihypertensive pharmaceutical medications available, their side effects and negative consequences cannot be ignored. Therefore, studying the etiology and pathogenesis of hypertension to develop a novel method for the treatment of these patients remains an urgent need. In this study, the role and mechanism of CaSR in the regulation of the vascular tone in SHRs were preliminary analyzed with respect to the $\mathrm{PLC}-\mathrm{IP}_{3} / \mathrm{AC}-\mathrm{V} / \mathrm{cAMP} / \mathrm{RAS}$ pathway. We demonstrated the following: i) CaSR is functionally expressed in the MA, and CaSR expression is decreased in SHRs; ii) vasoconstriction is enhanced, and vasodilatation is attenuated in SHRs, which is endothelium-independent; and 
Table II. Effect of pretreatment with PLC-IP $3 / \mathrm{AC}-\mathrm{V} / \mathrm{cAMP} / \mathrm{RAS}$ pathway inhibitors on vascular reactivity.

\begin{tabular}{|c|c|c|c|}
\hline Rat & Group & $\operatorname{Emax}(\%)$ & $\mathrm{IC}_{50}(\mu \mathrm{M})$ \\
\hline \multirow[t]{10}{*}{ WKY } & $\mathrm{PE}+\mathrm{U} 73122$ & $30.86 \pm 1.70^{\mathrm{a}}$ & $0.61 \pm 0.15$ \\
\hline & $\mathrm{PE}+2 \mathrm{APB}$ & $24.05 \pm 2.25^{\mathrm{a}}$ & $2.86 \pm 0.33$ \\
\hline & PE + MDL12330A & $20.66 \pm 2.95^{\mathrm{a}}$ & $0.78 \pm 0.33$ \\
\hline & $\mathrm{PE}+\mathrm{CAP}$ & $30.08 \pm 3.46^{\mathrm{a}}$ & $0.77 \pm 0.29$ \\
\hline & $\mathrm{PE}+\mathrm{LOS}$ & $30.49 \pm 1.44^{\mathrm{a}}$ & $0.51 \pm 0.07$ \\
\hline & Ach + U73122 & $61.12 \pm 1.64^{\mathrm{b}}$ & $-1.78 \pm 0.12$ \\
\hline & $\mathrm{Ach}+2 \mathrm{APB}$ & $63.69 \pm 1.04^{\mathrm{b}}$ & $-2.72 \pm 0.74$ \\
\hline & Ach + MDL12330A & $73.14 \pm 4.41^{\mathrm{b}}$ & $-1.15 \pm 0.19$ \\
\hline & Ach + CAP & $67.68 \pm 6.15^{b}$ & $-2.74 \pm 4.78$ \\
\hline & Ach + LOS & $58.22 \pm 0.90^{\mathrm{b}}$ & $-4.78 \pm 3.52$ \\
\hline \multirow[t]{10}{*}{ SHR } & $\mathrm{PE}+\mathrm{U} 73122$ & $36.65 \pm 0.51^{\mathrm{c}}$ & $1.32 \pm 0.03$ \\
\hline & $\mathrm{PE}+2 \mathrm{APB}$ & $12.18 \pm 2.92^{\mathrm{c}}$ & $2.13 \pm 1.16$ \\
\hline & $\mathrm{PE}+\mathrm{MDL} 12330 \mathrm{~A}$ & $11.89 \pm 1.44^{\mathrm{c}}$ & $0.98 \pm 0.24$ \\
\hline & $\mathrm{PE}+\mathrm{CAP}$ & $31.36 \pm 2.42^{\mathrm{c}}$ & $0.58 \pm 0.09$ \\
\hline & $\mathrm{PE}+\mathrm{LOS}$ & $31.01 \pm 1.99^{c}$ & $0.61 \pm 0.14$ \\
\hline & Ach + U73122 & $67.48 \pm 3.43$ & $-0.72 \pm 0.04$ \\
\hline & $\mathrm{Ach}+2 \mathrm{APB}$ & $66.12 \pm 8.76^{\mathrm{d}}$ & $-2.08 \pm 0.30$ \\
\hline & Ach + MDL12330A & $57.97 \pm 5.82^{\mathrm{d}}$ & $-2.13 \pm 0.14$ \\
\hline & Ach + CAP & $50.70 \pm 3.67^{d}$ & $-1.86 \pm 0.02$ \\
\hline & Ach + LOS & $52.70 \pm 1.78^{\mathrm{d}}$ & $-1.67 \pm 0.08$ \\
\hline \multirow[t]{10}{*}{ WKY } & $\mathrm{PE}+\mathrm{U} 73122-\mathrm{E}$ & $39.98 \pm 0.92^{\mathrm{e}}$ & $0.41 \pm 0.07$ \\
\hline & $\mathrm{PE}+2 \mathrm{APB}-\mathrm{E}$ & $53.29 \pm 1.68^{\mathrm{e}}$ & $-0.19 \pm 0.08$ \\
\hline & $\mathrm{PE}+\mathrm{MDL} 12330 \mathrm{~A}-\mathrm{E}$ & $41.26 \pm 1.20^{\mathrm{e}}$ & $0.39 \pm 0.04$ \\
\hline & $\mathrm{PE}+\mathrm{CAP}-\mathrm{E}$ & $33.25 \pm 2.18^{\mathrm{e}}$ & $0.53 \pm 0.10$ \\
\hline & $\mathrm{PE}+\mathrm{LOS}-\mathrm{E}$ & $39.85 \pm 2.29^{\mathrm{e}}$ & $0.64 \pm 0.07$ \\
\hline & $\mathrm{SNP}+\mathrm{U} 73122$ & $18.57 \pm 18.57^{\mathrm{f}}$ & $-1.16 \pm 0.21$ \\
\hline & $\mathrm{SNP}+2 \mathrm{APB}$ & $45.85 \pm 4.13^{\mathrm{f}}$ & $-0.15 \pm 0.34$ \\
\hline & $\mathrm{SNP}+\mathrm{MDL} 12330 \mathrm{~A}$ & $33.17 \pm 0.97^{f}$ & $-1.14 \pm 0.25$ \\
\hline & $\mathrm{SNP}+\mathrm{CAP}$ & $35.90 \pm 16.53^{f}$ & $0.7 \pm 1.45$ \\
\hline & $\mathrm{SNP}+\mathrm{LOS}$ & $34.62 \pm 6.52^{\mathrm{f}}$ & $0.13 \pm 0.49$ \\
\hline \multirow[t]{10}{*}{ SHR } & $\mathrm{PE}+\mathrm{U} 73122-\mathrm{E}$ & $36.41 \pm 3.02^{\mathrm{g}}$ & $0.74 \pm 0.07$ \\
\hline & $\mathrm{PE}+2 \mathrm{APB}-\mathrm{E}$ & $25.48 \pm 1.80^{\mathrm{g}}$ & $0.83 \pm 0.06$ \\
\hline & PE + MDL12330A-E & $38.12 \pm 0.97^{\mathrm{g}}$ & $0.46 \pm 0.07$ \\
\hline & $\mathrm{PE}+\mathrm{CAP}-\mathrm{E}$ & $33.46 \pm 2.12^{\mathrm{g}}$ & $0.4 \pm 0.12$ \\
\hline & $\mathrm{PE}+\mathrm{LOS}-\mathrm{E}$ & $38.35 \pm 0.73^{\mathrm{g}}$ & $0.52 \pm 0.07$ \\
\hline & $\mathrm{SNP}+\mathrm{U} 73122$ & $49.27 \pm 0.76^{\mathrm{h}}$ & $-0.67 \pm 0.07$ \\
\hline & $\mathrm{SNP}+2 \mathrm{APB}$ & $30.67 \pm 3.92^{\mathrm{h}}$ & $-1.14 \pm 0.44$ \\
\hline & $\mathrm{SNP}+\mathrm{MDL} 12330 \mathrm{~A}$ & $46.91 \pm 1.59$ & $-1.91 \pm 0.06$ \\
\hline & $\mathrm{SNP}+\mathrm{CAP}$ & $45.45 \pm 1.89$ & $-1.00 \pm 0.19$ \\
\hline & SNP +LOS & $45.68 \pm 1.21$ & $-0.53 \pm 0.13$ \\
\hline
\end{tabular}

The data are expressed as the mean \pm standard deviation $(\mathrm{n}=6)$. WKY PE groups vs. each signalling pathway inhibitor group, ${ }^{\text {aP }}<0.01 ; \mathrm{WKY}$ Ach groups vs. each signalling pathway inhibitor group, ${ }^{\text {} P}<0.01$; SHR PE groups vs. each signalling pathway inhibitor group, ${ }^{c} \mathrm{P}<0.01$; $\mathrm{SHR}$ Ach groups vs. $2 \mathrm{APB}$, MDL12330A, CAP, LOS groups, ${ }^{\mathrm{d}} \mathrm{P}<0.05$; WKY PE-E groups vs. each signalling pathway inhibitor group, ${ }^{\mathrm{e}} \mathrm{P}<0.01$; WKY SNP groups vs. each signalling pathway inhibitor group, ${ }^{\mathrm{f}} \mathrm{P}<0.01$; SHR $\mathrm{PE}-\mathrm{E}$ groups vs. each signalling pathway inhibitor group, ${ }^{\mathrm{g}} \mathrm{P}<0.01$; SHR SNP groups vs. each signalling pathway inhibitor group, ${ }^{\mathrm{h}} \mathrm{P}<0.01$. -E, endothelial removal; $\mathrm{IC}_{50}$, inhibitory concentration to exhibit 50\% of the maximum contraction and diastolic effect; WKY, Wistar Kyoto rats; SHR, spontaneously hypertensive rats; PE, phenylephrine; Ach, acetylcholine; SNP, sodium nitroprusside; PLC, phospholipase C; U73122, PLC inhibition; 2APB, 2-aminoethoxydiphenyl borate, IP3 inhibitor; MDL12330A, adenylyl cyclase V inhibitor; CAP, captopril, angiotensin-converting enzyme inhibitor; LOS, losartan, angiotensin II receptor type 1 inhibitor. 
A

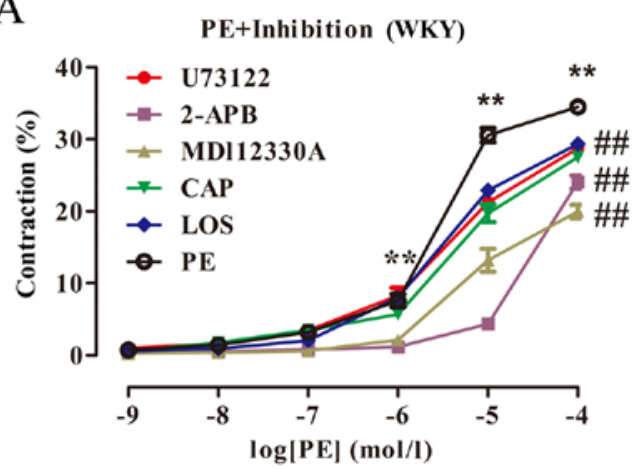

$\mathrm{C}$

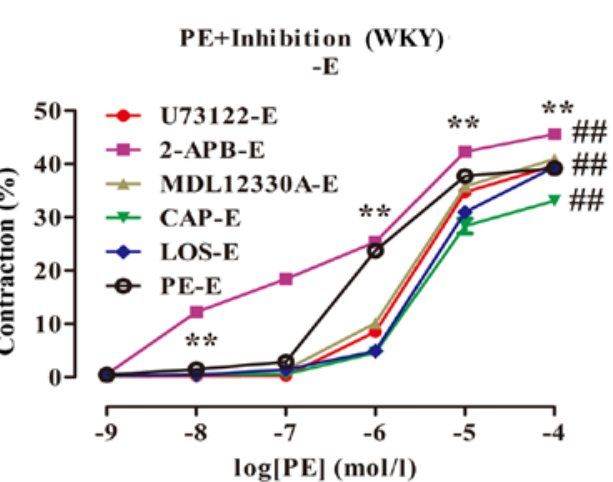

E

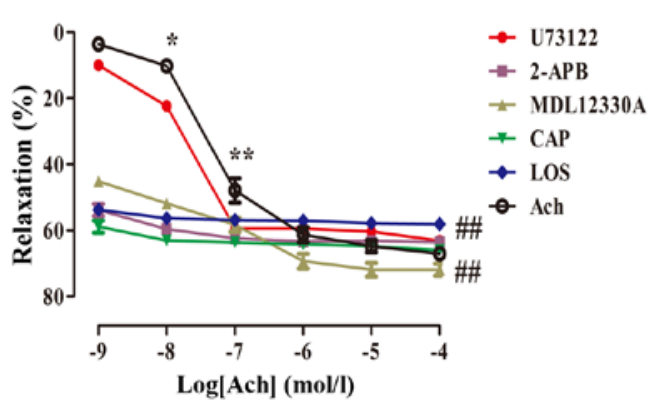

G SNP+Inhibition (WKY)

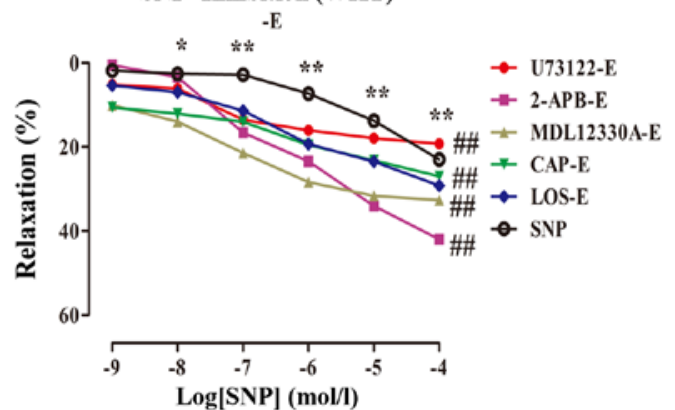

B PE+Inhibition (SHR)

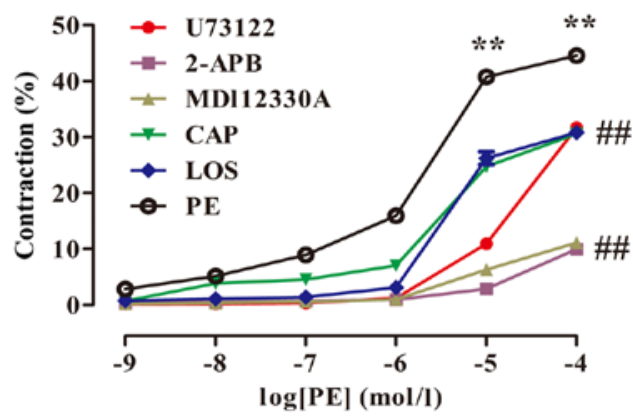

$\mathrm{D}$

PE+Inhibition (SHR)

$-\mathbf{E}$

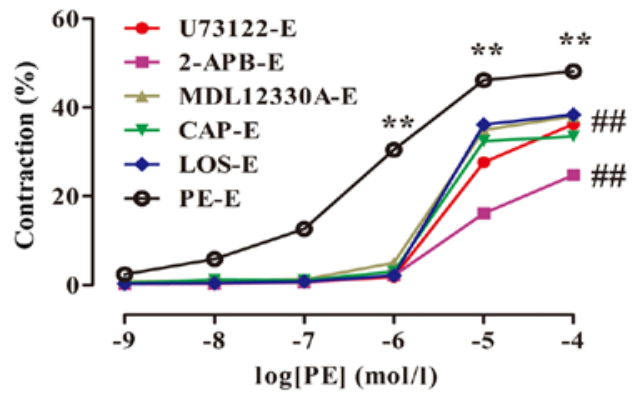

$\mathrm{F}$

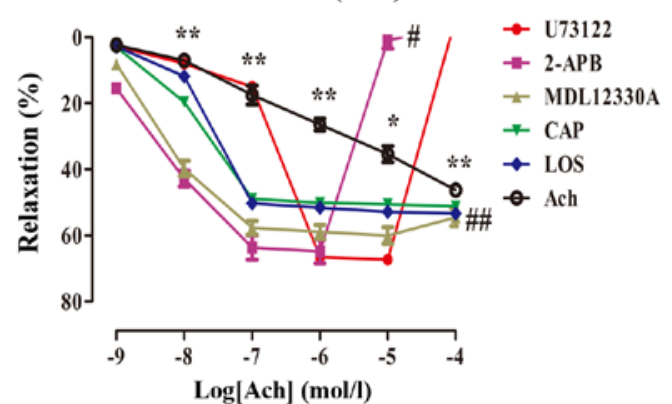

$\mathrm{H}$ SNP+Inhibition (SHR)

$-\mathrm{E}$

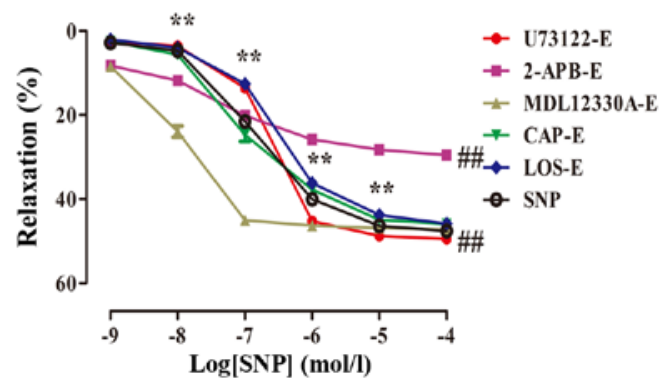

Figure 6. Effect of PLC-IP $/$ /AC-V/cAMP/RAS pathway inhibitors on vascular reactivity of the mesenteric artery in the WKY and SHR. The data are expressed as the mean \pm standard deviation (n=6). (A) WKY PE groups vs. each signalling pathway inhibitor group, ${ }^{\# \prime} \mathrm{P}<0.01$; (B) SHR PE groups vs. each signalling pathway inhibitor group, ${ }^{\#} \mathrm{P}<0.01$; (C) WKY PE-E groups vs. each signalling pathway inhibitor group, ${ }^{\# \#} \mathrm{P}<0.01$; (D) SHR PE-E groups vs. each signalling pathway inhibitor group, ${ }^{\# \#} \mathrm{P}<0.01$; (E) WKY Ach groups vs. each signalling pathway inhibitor group, ${ }^{\# \#} \mathrm{P}<0.01$; (F) SHR Ach group vs. U73122 groups, ${ }^{\text {\#P }}<0.05$; SHR Ach group vs. MDL12330A, CAP, LOS groups, ${ }^{\# \#} \mathrm{P}<0.01$; (G) WKY SNP groups vs. each signalling pathway inhibitor group, ${ }^{\# \#} \mathrm{P}<0.01$; (H) SHR SNP groups vs. each signalling pathway inhibitor group, ${ }^{\# \#} \mathrm{P}<0.01 .{ }^{*} \mathrm{P}<0.05,{ }^{* *} \mathrm{P}<0.01$, vs. the adjacent concentrations in each group. -E, endothelial removal; WKY, Wistar Kyoto rats; SHR, spontaneously hypertensive rats; PE, phenylephrine; Ach, acetylcholine; SNP, sodium nitroprusside; PLC, phospholipase C; U73122, PLC inhibitor; 2-APB, 2-aminoethoxydiphenyl borate, IP3 inhibitor; MDL12330A, adenylyl cyclase V inhibitor; CAP, captopril, ACE inhibitor; LOS, losartan, AT1R inhibitor.

iii) CaSR is involved in the regulation of BP and vascular tension in SHR and WKYs, which may be associated with differences in the underlying mechanisms, and this effect is partially endothelium-dependent. Furthermore, the effect was proposed to be mediated by the PLC-IP/AC-V/cAMP/RAS pathway. These data may provide novel insight into the 
Table III. Effects of CaSR inhibitors combined with $\mathrm{PLC}-\mathrm{IP}_{3} / \mathrm{AC}-\mathrm{V} / \mathrm{cAMP} / \mathrm{RAS}$ pathway inhibitors on MA reactivity in rats.

\begin{tabular}{|c|c|c|c|}
\hline Rat & Groups & $\operatorname{Emax}(\%)$ & $\mathrm{IC}_{50}(\mu \mathrm{M})$ \\
\hline \multirow[t]{10}{*}{ WKY } & $\mathrm{PE}+\mathrm{U} 73122+\mathrm{NPS} 2143$ & $4.01 \pm 0.86^{\mathrm{a}}$ & $0.56 \pm 0.70$ \\
\hline & $\mathrm{PE}+2 \mathrm{APB}+\mathrm{NPS} 2143$ & $6.14 \pm 4.59^{\mathrm{a}}$ & $1.14 \pm 1.24$ \\
\hline & PE + MDL12330A + NPS2143 & $4.06 \pm 1.27^{\mathrm{a}}$ & $0.45 \pm 0.09$ \\
\hline & $\mathrm{PE}+\mathrm{CAP}+\mathrm{NPS} 2143$ & $3.19 \pm 0.64^{\mathrm{a}}$ & $0.21 \pm 0.18$ \\
\hline & PE + LOS + NPS2143 & $3.33 \pm 0.54^{\mathrm{a}}$ & $0.44 \pm 0.18$ \\
\hline & Ach + U73122+NPS2143 & $25.59 \pm 2.86^{\mathrm{b}}$ & $-4.37 \pm 4.42$ \\
\hline & Ach + 2APB + NPS2143 & $28.02 \pm 3.02^{\mathrm{b}}$ & $-0.87 \pm 1.48$ \\
\hline & Ach + MDL12330A + NPS2143 & $27.07 \pm 2.80^{\mathrm{b}}$ & $-3.74 \pm 1.13$ \\
\hline & Ach + CAP + NPS2143 & $21.63 \pm 1.83^{\mathrm{b}}$ & $-4.51 \pm 2.59$ \\
\hline & Ach + LOS + NPS2143 & $25.04 \pm 0.62^{\mathrm{b}}$ & $-0.84 \pm 0.46$ \\
\hline \multirow[t]{10}{*}{ SHR } & $\mathrm{PE}+\mathrm{U} 73122+\mathrm{NPS} 2143$ & $24.42 \pm 2.21^{\mathrm{c}}$ & $0.33 \pm 0.15$ \\
\hline & $\mathrm{PE}+2 \mathrm{APB}+\mathrm{NPS} 2143$ & $5.53 \pm 2.76^{\mathrm{c}}$ & $0.66 \pm 0.64$ \\
\hline & PE + MDL12330A + NPS2143 & $4.22 \pm 3.12^{\mathrm{c}}$ & $0.58 \pm 0.50$ \\
\hline & $\mathrm{PE}+\mathrm{CAP}+\mathrm{NPS} 2143$ & $5.06 \pm 2.36^{c}$ & $0.82 \pm 0.80$ \\
\hline & $\mathrm{PE}+\mathrm{LOS}+\mathrm{NPS} 2143$ & $7.90 \pm 5.79^{c}$ & $1.27 \pm 1.26$ \\
\hline & Ach + U73122+NPS2143 & $59.25 \pm 8.86^{\mathrm{d}}$ & $-1.21 \pm 0.42$ \\
\hline & Ach + 2APB + NPS2143 & $67.29 \pm 7.48^{\mathrm{d}}$ & $-1.24 \pm 0.45$ \\
\hline & Ach + MDL12330A + NPS2143 & $60.76 \pm 8.35^{\mathrm{d}}$ & $-1.32 \pm 0.93$ \\
\hline & Ach + CAP+ NPS 2143 & $51.17 \pm 0.65^{\mathrm{d}}$ & $-1.24 \pm 0.24$ \\
\hline & Ach + LOS + NPS2143 & $54.57 \pm 3.22^{\mathrm{d}}$ & $-1.5 \pm 0.05$ \\
\hline
\end{tabular}

The data are expressed as the mean \pm standard deviation $(n=6)$. WKY PE + NPS2143 groups vs. each signalling pathway blocker group, ${ }^{\mathrm{a}} \mathrm{P}<0.01$; WKY Ach + NPS214 groups vs. each signalling pathway blocker group, ${ }^{\mathrm{b}} \mathrm{P}<0.01 ;$ SHR PE + NPS2143 groups vs. each signalling pathway blocker group, ${ }^{\mathrm{c}} \mathrm{P}<0.01$; SHR Ach $+\mathrm{NPS} 2143$ groups vs. each signalling pathway blocker group, ${ }^{\mathrm{d}} \mathrm{P}<0.01$. $\mathrm{IC}_{50}$, inhibitory concentration to exhibit $50 \%$ of the maximum contraction and diastolic effect; WKY, Wistar Kyoto rats; SHR, spontaneously hypertensive rats; PE, phenylephrine; Ach, acetylcholine; SNP, sodium nitroprusside; CaSR, calcium sensing receptor; NPS2143, CaSR inhibitor; PLC, phospholipase C; U73122, PLC inhibitor; 2APB, 2-aminoethoxydiphenyl borate, IP3 inhibitor; MDL12330A, adenylyl cyclase V inhibitor; CAP, captopril, angiotensin-converting enzyme inhibitor; LOS, losartan, angiotensin II receptor type 1 inhibitor.

regulatory mechanisms of CaSR in angiotasis in SHRs via the

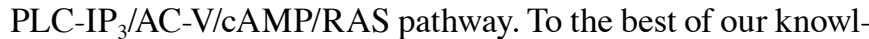
edge, the present study is the first to determine the mechanism underlying the role of CaSR in angiotasis in SHRs via the $\mathrm{PLC}-\mathrm{IP}_{3} / \mathrm{AC}-\mathrm{V} / \mathrm{cAMP} / \mathrm{RAS}$ pathway.

It has been reported that a rise in vascular tension is caused by an increase in peripheral vascular resistance, which is the key factor associated with the onset of hypertension (5). The small artery determines peripheral vascular resistance, and the microvascular segment is the key position for forming blood circulation resistance (5). The decrease in BP reaches $\leq 90 \%$, and myogenic tension changes between the capillary and small artery are the key factors of changes in peripheral vascular resistance and the formation of BP (41). In the current study, 2-3 sizes of the MA were selected (diameter: 300-500 $\mu \mathrm{m}$ ), which is a resistance vessel in the circulatory system and was in accordance with experimental requirements.

During the state of hypertension, the reactivity of vascular smooth muscle to vasoactive substances is enhanced (5), but this mechanism is not yet fully understood. In the present study, an internationally recognized animal model of hypertensive disease was used SHRs. It has been reported that SHRs comprise a hypertensive disease model with an enhanced vascular tone (42). Similar to human hypertension,
SHRs present with endothelial dysfunction and reduced NO bioavailability (43). To evaluate basic differences in angiotasis between SHR and WKY, and the effect of the vascular endothelium, the pressure myograph technique was used to assess changes in angiotasis in the MA of the rats. The present study determined that, whether the endothelium was intact or denuded, the contraction range in SHRs was higher than that in WKY. However, the vasoconstriction of the endothelium-denuded group was higher than that in the endothelium-intact group for the WKY. It is worth mentioning that vasoconstriction in the endothelium-denuded group compared with that in the endothelium-intact group markedly differed for WKYs and SHRs. This partially suggests that contractile enhancement in SHRs is endothelium-independent. For the endothelium-intact rats, the vasodilatory amplitude in SHRs was lower than that in WKYs. For the endothelium-denuded rats, the vasodilation amplitude in SHRs was greater than that in WKYs. We also demonstrated that the reduced vasodilation in SHRs was endothelium-independent. In conclusion, the increased vasoconstriction and reduced vasodilation in SHRs are endothelial-independent. These results are similar to other recent research reports and are in accordance with the pathophysiological pathogenesis of hypertension $(5,44)$. 
A

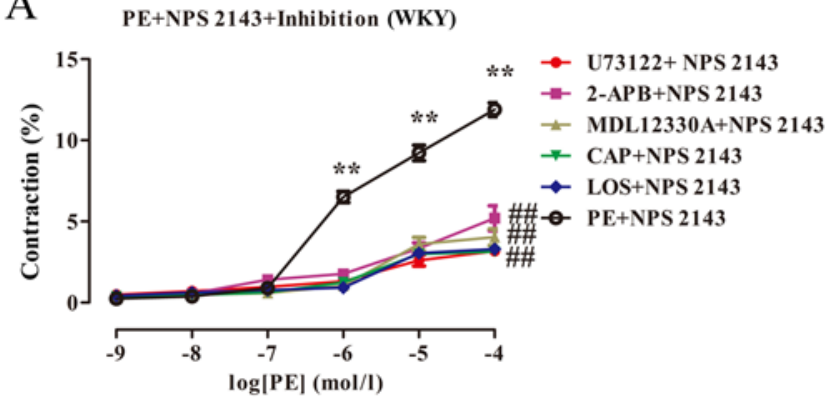

C

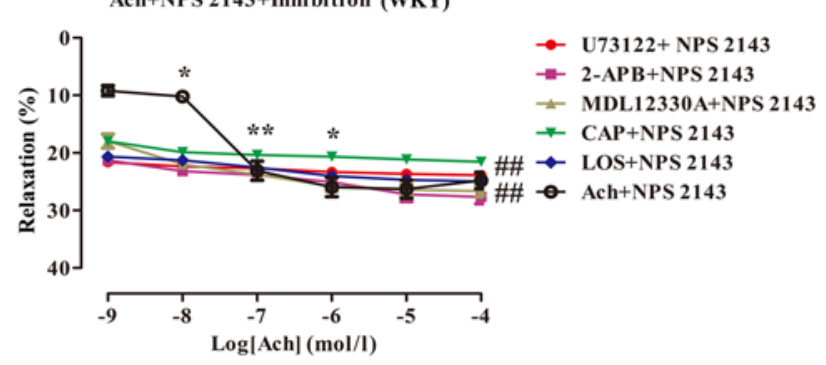

B

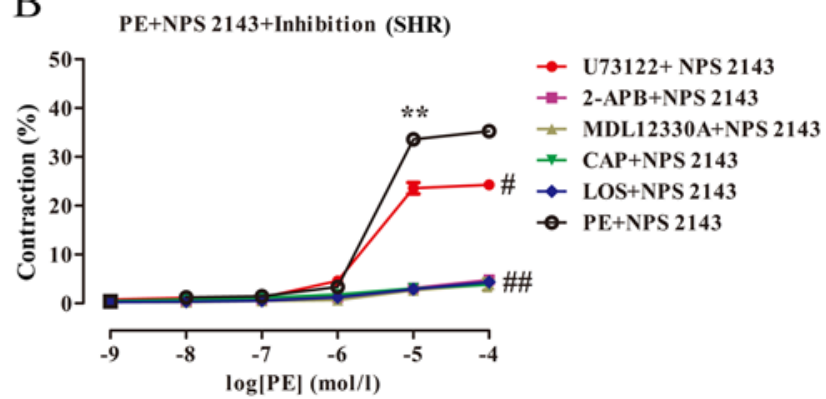

D

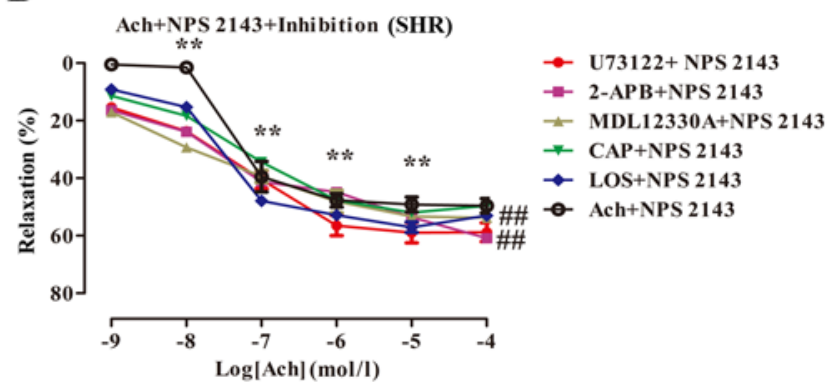

Figure 7. Effect of CaSR inhibitors combined with PLC-IP/AC-V/cAMP/RAS pathway inhibitor on vascular reactivity of the MA in the WKY and SHR. The data are expressed as the mean \pm standard deviation $(\mathrm{n}=6)$. (A) WKY PE + NPS2143 groups vs. each signalling pathway blocker group, ${ }^{\# /} \mathrm{P}<0.01 ;(\mathrm{B})$ SHR $\mathrm{PE}+$ NPS2143 groups vs. each signalling pathway blocker group, ${ }^{\# \#} \mathrm{P}<0.01 ;$ (C) In WKY Ach + NPS214 groups vs. each signalling pathway blocker group, ${ }^{\# \#} \mathrm{P}<0.01$; (D) SHR Ach + NPS2143 groups vs. each signalling pathway blocker group, ${ }^{\# \#} \mathrm{P}<0.01 .{ }^{*} \mathrm{P}<0.05,{ }^{* *} \mathrm{P}<0.01$, vs. the adjacent concentrations in each group. NPS2143, CaSR inhibitor; PLC, phospholipase C; U73122, PLC inhibitor; 2-APB, 2-aminoethoxydiphenyl borate, IP3 inhibitor; MDL12330A, adenylyl cyclase V inhibitor; CAP, captopril, ACE inhibitor; LOS, losartan, AT1R inhibitor.

The initiation of research on CaSR in the field of angiogenesis occurred relatively recently. In 2003, Wang et al (21) was the first to confirm that CaSR is expressed in the rat myocardium. With subsequent research, it was found that CaSR is functionally expressed in the outer membrane of the blood vessel wall, fibroblast, VSMCs, and endothelial cells, among others $(10,17,45)$. It was also found to serve a key role in the regulation of $\mathrm{BP}$ and angiotasis, but the mechanism was not clear. The present study suggests that hormones (renin, parathyroid hormone), $\left[\mathrm{Ca}^{2+}\right]_{0}, \mathrm{CaSR}$, vascular calcification, the nervous system, and certain agents are involved in the regulation of BP and vascular tone. In 1911, Cow revealed that the relaxation of isolated blood vessels is mediated by an increase of $\left[\mathrm{Ca}^{2+}\right]_{0}$. Furthermore, Wang and Bukoski (46) reported that $\left[\mathrm{Ca}^{2+}\right]_{0}$ can induce the relaxation of the MA, coronary artery, renal artery and cerebral artery in rats. In addition, other CaSR calcimimetics (like $\mathrm{Mg}^{2+}$ and neomycin) have similar vasodilatory effects (47). In contrast, Ohanian et al (48) found that $\left[\mathrm{Ca}^{2+}\right]_{0}$ can induce two-way effects in subcutaneous arterioles in rats, which suggests that low concentrations of $\left[\mathrm{Ca}^{2+}\right]_{\text {o }}$ $(0.5-2 \mathrm{mmol} / \mathrm{l}) \mathrm{can}$ induce the contraction of small arteries and that high concentrations of $\left[\mathrm{Ca}^{2+}\right]_{0}(3-10 \mathrm{mmol} / \mathrm{l})$ can induce the relaxation of small arteries. It was shown that pre-incubation with the CaSR inhibitor NPS2143 attenuates $\mathrm{KCl}$ and PE-induced vasoconstriction in oxygen-poor/oxygen-rich MAs; however, NPS2143 did not improve the endothelium-dependent relaxation induced by Ach (49). To evaluate the angiotasis-mediated regulation of CaSR and its effect on the vascular endothelium, the pressure myograph technique was used to observe changes in angiotasis with CaSR calcimimetics and inhibitors in the MA of rats. Our results showed that in endothelium-intact vessels, pre-incubation with
NPS2143 induced vasoconstriction in the MA and that the contraction degree of vasoconstriction in the WKY group was higher than that in SHRs. Pre-incubation with NPSR568 also induced vasodilation in the MA, and the degree of relaxation in the endothelium-intact group was higher than that in the endothelium-denuded group. In the MA of rats, with different concentrations of NPSR568, whether the endothelium was intact or denuded, vasoconstriction could be inhibited and vasodilation was enhanced. The effect of NPSR568 $(10 \mu \mathrm{M})$ was also the most obvious; however, NPS2143 could also inhibit vasoconstriction and enhance vasodilation. Regardless of whether the endothelium was intact or denuded, the degree of contraction in SHRs was higher than that in WKYs. Furthermore, the enhancement of NPS2143-induced vasodilation was significantly different between the WKY and SHR groups. When the endothelium was intact, NPS2143 enhanced vasodilation in WKYs to a higher degree than that in SHRs. When the endothelium was denuded, vasodilation in WKYs was lower than that in SHRs. This suggested that NPSR568 and NPS2143 both alleviated vasoconstriction of the MA in SHRs. Among them, for NPS2143, the alleviating effect in SHRs was decreased compared with that in WKYs, and this was partly endothelium-dependent. For NPSR568, the vasodilatory inducing effect in SHRs was partly endothelium-dependent; however, the inhibitory effect of NPS2143 on vasodilation in WKYs was endothelium-independent. Our experimental results were similar to the aforementioned reports $(50,51)$. For NPSR568, the previously mentioned two-way effects were not observed with concentrations of 0.01-10 $\mu \mathrm{M}$, which may be related to the experimental animals, experimental conditions, detection methods, types of calcimimetics (the calcimimetic used to delineate the previously mentioned two-way effects 


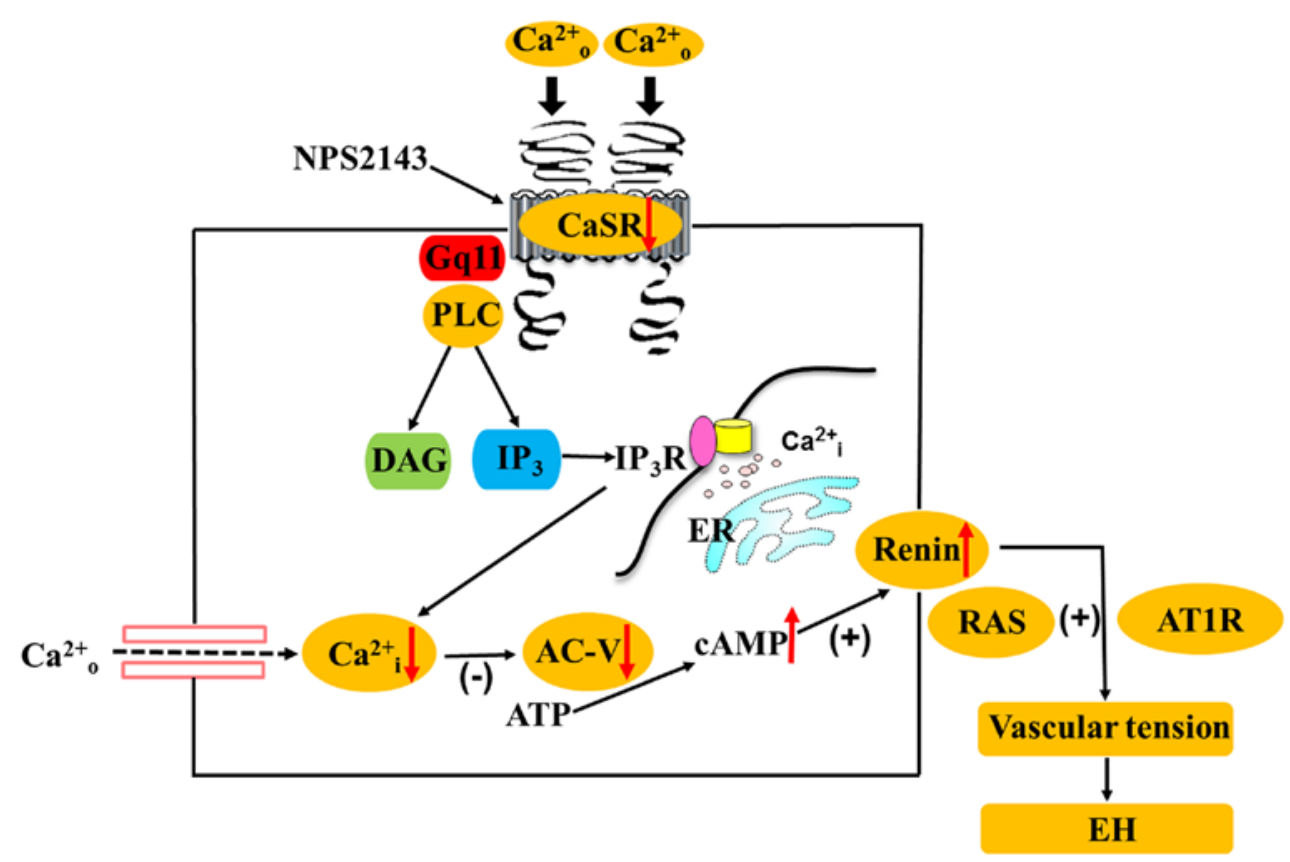

Figure 8. Hypothetical mechanism is the calcium sensing receptor participates in the regulation of vascular tension in the mesentery of hypertensive rats via the PLC- $\mathrm{IP}_{3} / \mathrm{AC}-\mathrm{V} / \mathrm{cAMP} / \mathrm{RAS}$ pathway. CaSR, calcium sensing receptor; PLC, phospholipase $\mathrm{C}$; $\mathrm{IP}_{3}$, inositol 1,4,5-triphosphate; AC-V, adenylate cyclase-V; cAMP, cyclic adenosine monophosphate; RAS, renin-angiotensin system; AT1R, angiotensin II receptor type 1 ; [Ca $\left.{ }^{2+}\right]_{0}$, increased extracellular $\left.\mathrm{Ca}^{2+} ; \mathrm{Ca}^{2+}\right]_{\mathrm{i}}$, intracellular $\mathrm{Ca}^{2+}$; NPS2143, calcium sensing receptor inhibitor; DAG, diphosphoglycerate; ER, endoplasmic reticulum; IP $\mathrm{R}_{3}$, inositol 1,4,5-triphosphate receptor; ATP, adenosine triphosphate; Gq11, G protein-coupled receptor.

was $\mathrm{Ca}^{2+}$ ), and the concentrations of drugs. Of note, with a concentration of $10^{-5} \mathrm{~mol} / 1$, NPSR568 and NPS2143 had similar effects, specifically the inhibition of vasoconstriction in SHRs. This indicated that this vessel regulatory effect was not completely induced by CaSR and that it may be due to the specific effects of the agent itself. Our research supported this concept. When the concentration of the NPS2143 was $10^{-5} \mathrm{~mol} / \mathrm{l}$, the drug itself caused maximum vasoconstriction in SHRs and WKYs. Conversely, for NPSR568 at a concentration of $10^{-5} \mathrm{~mol} / \mathrm{l}$, the drug itself caused maximum vasodilation in SHRs. Denuding the endothelium abolished vasodilation, which indicated that this partly relied on the NO produced by the endothelium. Similar to our research results, other reports have proposed that, except for changes in angiotasis induced by CaSR, the CaSR calcimimetic can also inhibit vascular reactivity via a CaSR-dependent mechanism by directly blocking the voltage-dependent L-type calcium channels (VGCCs). Importantly, both the CaSR-dependent and CaSR-independent effects are likely to occur at similar concentrations (49). Nakagawa et al (50) found that the CaSR calcimimetics R-568 and S-568 have similar BP-reducing effects in rats; however, S-568 markedly unaffects CaSR. Thus, it is considered that the BP-reducing effect of R-568 is not induced by CaSR. Taken together, these results indicate that the NPSR568 and NPS2143 can modulate the vascular tone in SHRs and WKYs via different regulatory mechanisms, which is partially endothelium-dependent and partly mediated by CaSR. The reason for this effect may be associated with the similarities in the molecular structure of the allosteric modulators of CaSR. The negative allosteric modulator NPS2143 is known to be structurally related to phenylalkylamines and has a positively charged amino group $(52,53)$. The positive allosteric modulator
NPSR568 is a phenylalkylamine derivative, which is a potent VGCC blocker that exhibits weak allosteric potentiation of the CaSR $(50,53,54)$. This structural similarity is highlighted by the fact that NPS2143 and NPSR568 both target a common allosteric site within the seventh transmembrane domain of CaSR (49).

Increased $\left[\mathrm{Ca}^{2+}\right]_{0}$ induces binding to the CaSR and activates the G-protein-PLC- $\mathrm{IP}_{3}$ pathway, promoting the influx of extracellular $\mathrm{Ca}^{2+}$; it also participates in the regulation of myocardial excitation-contraction coupling, which is the mechanism of $\mathrm{Ca}^{2+}$ overload in cells. $\mathrm{Ca}^{2+}$ overload in VSMCs can cause vasospasm, vascular wall thickening, vascular inflammation and other diseases. Additionally, it is related to hypertension, atherosclerosis and other diseases (9). The CaSR calcimimetic $\left[\mathrm{Ca}^{2+}\right]_{0}, \mathrm{Gd}^{3+}$ and spermine can cause $\mathrm{Ca}^{2+}$ to be released from the myocardial cytoplasmic reticulum of rats through the $\mathrm{G}$ protein-PLC-IP 3 pathway (21). In conclusion, the $\mathrm{G}$ protein-PLC-IP 3 pathway is involved in the regulation of a multi-level organization system. Based on the backgrounds of these studies, our research group proposed that CaSR might regulate angiotasis and BP in SHRs via the G protein-PLC-IP pathway, in which we investigated in the present study. Based on the alleviating effects of CaSR on vasoconstriction in SHRs and WKYs induced by PE, U73122 and 2-APB were administered to modulate the $\mathrm{G}$ protein-PLC-IP 3 pathway; with this, constriction in the two groups of rats was reduced. However, upon co-incubating the inhibitors NPS2143 and U73122, as well as 2-APB separately, constriction of the MA was reduced further. This result suggests that blocking the $\mathrm{G}$ protein-PLC-IP 3 pathway can strengthen the aforementioned vasoconstrictive effects of NPS2143. In other words, this pathway is the most important signalling pathway that 
relieves vasoconstriction in SHRs and WKYs. Furthermore, its mechanism is related to vasoconstriction caused by CaSR excitation, which is inhibited by NPS2143, and the release of reducing $\left[\mathrm{Ca}^{2+}\right]_{\mathrm{i}}$ due to the $\mathrm{G}$ protein-PLC-IP 3 pathway being blocked by PLC and $\mathrm{IP}_{3}$ inhibitors. The results of this study with respect to the vasodilation response are as described previously: Specifically, the NPS2143 enhanced vasodilatation in SHRs, but the inhibition of vasodilatation in WKYs was endothelium-independent. In the endothelium-denuded group, with the collaborative use of L-NAME and indomethacin, NPS2143 incubated vessels, which enhanced vasodilatation in the SHR and WKY groups. An exogenous NO donor, SNP, induced the same vascular reaction in SHRs and reversed its inhibitory effects on vasodilatation in WKYs, which indicated that the exogenous NO pathway is involved in the vasodilatation-enhancing effects of CaSR. Based on this, to further assess the regulatory mechanism of CaSR on vasodilatation, NPS2143 was incubated with U73122 and 2-APB separately. The results showed that the enhancing effects on vasodilatation of NPS2143 were further promoted, and this also reversed the vasodilatation-inhibitory effects in WKYs. It is noteworthy that in the endothelium-denuded group, the vasodilatory growth rate in WKYs induced by 2-APB was significantly higher than that in the other inhibitor groups. However, when the concentration of U73122 was $10^{-7} \mathrm{~mol} / \mathrm{l}$, the vasodilatory growth rate in the SHRs was the highest, after which, the vasodilatory growth rate reduced, but remained higher than the other inhibitor groups. This result implied that the $\mathrm{G}$ protein-PLC-IP 3 pathway is one endothelium-independent mechanism through which CaSR enhances vasodilatation in SHRs and WKYs. However, it remains unknown if other mechanisms are involved.

RAS, which is well-known, serves an important role in the regulation of human $\mathrm{BP}$ and the pathogenesis of hypertension. Renin is the first rate-limiting enzyme of the RAS system, and cAMP functions as a key effector in this system (14). In this system, another key factor ACE, catalyzes angiotensin I (AngI) conversion into angiotensin II (AngII), which exerts its biological effects by binding to AT1R. In vitro analysis suggested that AngII can increase the catecholamine level via AT1R and can serve a key role in the vasoconstriction induced by PE (55). Angiotensin-converting enzyme inhibitors (ACEI) and captopril can lower the mortality rate associated with hypertension and the complications from myocardial infarction, diabetes, cardiac failure and other conditions (56). Maeso et al (57) found that losartan can inhibit the contraction of the aorta from PE to rats and relies on NO from the vascular endothelium. This endothelium-denuded inhibitory effect disappeared; however, the side effects of classical ACE inhibitors, an AngII receptor blocker, and other antihypertensive agents, such as electrolyte imbalance, angioedema, cough and hypotension, might limit the use of these drugs (41). It is thus particularly important to develop a better treatment method.

The analysis of cultured MA VSMCs led to the identification of different components of the RAS (58). Research has shown that $\left[\mathrm{Ca}^{2+}\right]_{\mathrm{o}}$ and $\left[\mathrm{Ca}^{2+}\right]_{\mathrm{i}}$ are inversely proportional to renin (15). The associated mechanism is that CaSR causes a rise in $\left[\mathrm{Ca}^{2+}\right]_{\mathrm{i}}$ by activating the $\mathrm{G}$ protein-PLC-IP pathway, and inhibits $\mathrm{AC}-\mathrm{V}$ and reduces cAMP at the same time, which is related to the inhibition of renin release (12).
At first, our research group found an inverse relationship between CaSR and cAMP with RAS in the thoracic aorta of SHRs (18). To further assess the regulatory mechanism of CaSR in SHR angiotasis, CaSR was separately combined with MDL12330A, CAP and LOS, and administered to the vessels. Similar results were reported in the blocking effects of U73122 and 2-APB on the PLC-IP 3 pathway. The vasoconstriction in SHRs and WKYs was notably diminished with mild contraction, and even no contraction in parts of the vessels; however, vasodilatation was enhanced significantly. Furthermore, a low concentration of Ach was found to mediate complete vasodilatation. Among them, a low concentration of CAP $\left(10^{-9} \mathrm{~mol} / \mathrm{l}\right)$ induced vasodilation in WKYs, but the growth rate of vasodilation was significantly lower than in the other inhibitor groups. Collectively, the observations described herein support the hypothesis that CaSR participates in angiotasis regulation in SHRs and WKYs via the $\mathrm{PLC}-\mathrm{IP}_{3} / \mathrm{AC}-\mathrm{V} / \mathrm{cAMP} / \mathrm{RAS}$ pathway (Fig. 8). At present, the limitations of this study were mainly that direct in vitro experiments were conducted based on vascular administration with no in vivo analyses. Given the differences between the in vivo and in vitro experimental studies, our results have certain shortcomings. Despite these limitations, our research also partly explained the regulatory mechanism through which CaSR mediates angiotasis during hypertension via the PLC-IP 3 /AC-V/cAMP/RAS pathway.

In summary, CaSR is closely related to $\mathrm{BP}$ and angiotasis, and is involved in the regulation of these processes based on multi-molecular mechanisms and different pathways. Our research results show that $\mathrm{CaSR}$ is involved in the regulation of BP and vascular tension in SHRs and WKYs, which are associated with mechanistic differences and that this effect is partially endothelium-dependent. Specifically, the effect is mediated by the PLC-IP $3 / \mathrm{AC}-\mathrm{V} / \mathrm{cAMP} / \mathrm{RAS}$ pathway. Our findings provide a novel theoretical foundation for the mechanism of action underlying the relationship between CaSR, BP and angiotasis, and suggests drug targets for the prevention of hypertension and vessel-related diseases.

\section{Acknowledgements}

The authors would like to thank Dr Fang He (China Shihezi University, Shihezi, China) for technical support and critical review of the manuscript.

\section{Funding}

The project was supported by grants from the National Natural Science Foundation of China (grant no. 31560287).

\section{Availability of data and materials}

The datasets used and/or analyzed during the present study are available from the corresponding author on reasonable request.

\section{Authors' contributions}

WZ and RS contributed equally in reviewing the publications and writing this manuscript. WZ and FH contributed to the conception and design of the study. WZ and RS performed 
the experiments. $\mathrm{WZ}$ and $\mathrm{HZ}$ and wrote the paper. $\mathrm{YZ}$ and TZ performed and analyzed western blotting. NT, HZ and YL measured and analyzed blood pressure and vascular tone values. FH revised the manuscript and have given final approval of the version to be published.

\section{Ethics approval and consent to participate}

All animal experiments have been approved and supervised by Xinjiang Policy Experimental Animal Health and Use Committee.

\section{Patient consent for publication}

Not applicable.

\section{Competing interests}

The authors declare that they have no competing interests.

\section{References}

1. Lim S, Vos T and Bruce N: 'The burden of disease and injury attributable to 67 risk factors and risk factor clusters in 21 regions 1990-2010: A systematic analysis.' Lancet 380: 2224-2260, 2012.

2. Akpunonu BE, Mulrow PJ and Hoffman EA: Secondary hypertension: Evaluation and treatment. Dis Mon 42: 609-722, 1996.

3. WRITING GROUP MEMBERS, Lloyd-Jones D, Adams RJ, Brown TM, Carnethon M, Dai S, De Simone G, Ferguson TB Ford E, Furie K, et al: Heart disease and stroke statistics-2008 Update: A report from the american heart association statistics committee and stroke statistics subcommittee. Circulation 121: e46-e215, 2009.

4. Sharp SI, Aarsland D, Day S Nnesyn H; Alzheimer's Society Vascular Dementia Systematic Review Group and Ballard C: Hypertension is a potential risk factor for vascular dementia: Systematic review. Int J Geriatr Psychiatry 26: 661-669, 2011.

5. Figueroa XF, Isakson BE and Duling BR: Vascular gap junctions in hypertension. Hypertension 48: 804-811, 2006.

6. Allender PS, Cutler JA, Follmann D, Cappuccio FP, Pryer J and Elliott P: Dietary calcium and blood pressure: A meta-analysis of randomized clinical trials. Ann Intern Med 124: 825-831, 1996.

7. He K, Liu K, Daviglus ML, Morris SJ, Loria CM, Van Horn L, Jacobs DR Jr and Savage PJ: Magnesium intake and incidence of metabolic syndrome among young adults. Circulation 113 : 1675-1682, 2006.

8. Ayachi S: Increased dietary calcium lowers blood pressure in the spontaneously hypertensive rat. Metabolism 28: 1234-1238, 1979

9. Brown EM, Gamba G, Riccardi D, Lombardi M, Butters R, Kifor O, Sun A, Hediger MA, Lytton J and Hebert SC: Cloning and characterization of an extracellular $\mathrm{Ca}(2+)$-sensing receptor from bovine parathyroid. Nature 366: 575-580, 1993.

10. Weston AH, Geraghty A, Egner I and Edwards G: The vascular extracellular calcium-sensing receptor: An update. Acta Physiol (Oxf) 203: 127-137, 2011

11. Weston AH, Absi M, Ward DT, Ohanian J, Dodd RH, Dauban P, Petrel C, Ruat M and Edwards G: Evidence in favor of a calcium-sensing receptor in arterial endothelial cells. Circ Res 97: 391-398, 2005.

12. Ortiz-Capisano MC, Reddy M, Mendez M, Garvin JL and Beierwaltes WH: Juxtaglomerular cell CaSR stimulation decreases renin release via activation of the $\mathrm{PLC} / \mathrm{IP}_{3}$ pathway and the ryanodine receptor. Am J Physiol Renal Physiol 304 F248-F256, 2013.

13. Brown EM and Macleod RJ: Extracellular calcium sensing and extracellular calcium signaling. Physiol Rev. 81: 239-297, 2001.

14. Churchill PC: Second messengers in renin secretion. Am J Physiol 249: 175-184, 1985.

15. Atchison DK, Ortiz-Capisano MC and Beierwaltes WH: Acute activation of the calcium-sensing receptor inhibits plasma renin activity in vivo. Am J Physiol Regul Integr Comp Physiol 299: R1020-R1026, 2010
16. Park CS, Honeyman TW, Chung ES, Lee JS, Sigmon DH and Fray JC: Involvement of calmodulin in mediating inhibitory action of intracellular $\mathrm{Ca}^{2+}$ on renin secretion. Am J Physiol 251: F1055-F1062, 1986.

17. Smajilovic S, Yano S, Jabbari R and Tfelthansen J: The calcium-sensing receptor and calcimimetics in blood pressure modulation. Br J Pharmacol 164: 884-893, 2011.

18. Qu Y, Jing H, Wang LM, Tang N, Zhong H, Liu YM, Li Z, Feng Q and He F: Reduced expression of the extracellular calcium-sensing receptor (CaSR) is associated with activation of the renin-angiotensin system (RAS) to promote vascular remodeling in the pathogenesis of essential hypertension. PLoS One 11: e0157456, 2016.

19. Smajilovic $S$ and Tfelt-Hansen J: Novel role of the calcium-sensing receptor in blood pressure modulation. Hypertension 52: 994-1000, 2008.

20. Cow D: Some reactions of surviving arteries. J Physiol 42: 125-143, 1911.

21. Wang R, Xu C, Zhao W, Zhang J, Cao K, Yang B and Wu L: Calcium and polyamine regulated calcium-sensing receptors in cardiac tissues. Eur J Biochem 270: 2680-2688, 2003.

22. Loot AE, Pierson I, Syzonenko T, Elgheznawy A, Randriamboavonjy V, Zivković A, Stark $\mathrm{H}$ and Fleming I: $\mathrm{Ca}^{2+}$-sensing receptor cleavage by calpain partially accounts for altered vascular reactivity in mice fed a high-fat diet. J Cardiovasc Pharmacol 61: 528-535, 2013.

23. Ziegelstein RC, Xiong Y, He C and Hu Q: Expression of a functional extracellular calcium-sensing receptor in human aortic endothelial cells. Biochem Biophys Res Commun 342: 153-163, 2006.

24. Weston AH, Absi M, Ward DT, Ohanian J, Dodd RH, Dauban P, Petrel C, Ruat M and Edwards G: Evidence in favor of a calcium-sensing receptor in arterial endothelial cells: Studies with calindol and Calhex 231. Circ Res 97: 391-398, 2005.

25. Vizard TN, O'Keeffe GW, Gutierrez H, Kos CH, Riccardi D and Davies AM: Regulation of axonal and dendritic growth by the extracellular calcium-sensing receptor. Nat Neurosci 11: 285-291, 2008

26. Finn R: New animal care guide leaves details to scientists' discretion-the scientist-magazine of the life sciences. Scientist 10: 1996.

27. Chen YC, Yuan TY, Zhang HF, Wang DS, Niu ZR, Li L, Fang LH and Du GH: Fasudil evokes vasodilatation of rat mesenteric vascular bed via $\mathrm{Ca}(2+)$ channels and $\mathrm{Rho} / \mathrm{ROCK}$ pathway. Eur J Pharmacol 788: 226-233, 2016.

28. Choi S, Ryu KH, Park SH, Jun JY, Shin BC, Chung JH and Yeum CH: Direct vascular actions of quercetin in aorta from renal hypertensive rats. Kidney Res Clin Pract 35: 15-21, 2016.

29. Zhu XM, Fang LH, Li YJ and Du GH: Endothelium-dependent and -independent relaxation induced by pinocembrin in rat aortic rings. Vascul Pharmacol 46: 160-165, 2007.

30. Saito M, Tsounapi P, Oikawa R, Shimizu S, Honda M, Sejima T, Kinoshita Y and Tomita S: Prostatic ischemia induces ventral prostatic hyperplasia in the SHR; possible mechanism of development of BPH. Sci Rep 4: 3822, 2014.

31. Wonneberger K, Scofield MA and Wangemann P: Evidence for a calcium-sensing receptor in the vascular smooth muscle cells of the spiral modiolar artery. J Membr Biol 175: 203-212, 2000.

32. Chan YC, Leung FP, Wong WT, Tian XY, Yung LM, Lau CW, Tsang SY, Yao X, Chen ZY and Huang Y: Therapeutically relevant concentrations of raloxifene dilate pressurized rat resistance arteries via calcium-dependent endothelial nitric oxide synthase activation. Arterioscler Thromb Vasc Biol 30: 992-999, 2010.

33. Caniffi C, Cerniello FM, Gobetto MN, Sueiro ML, Costa MA and Arranz C: Vascular tone regulation induced by C-type natriuretic peptide: Differences in endothelium-dependent and -independent mechanisms involved in normotensive and spontaneously hypertensive rats. PLoS One 11: e0167817, 2016.

34. Sudhahar V, Shaw S and Imig JD: Mechanisms involved in oleamide-induced vasorelaxation in rat mesenteric resistance arteries. European J Pharmacol 607: 143, 2009.

35. Musha Y, Itoh S, Hanson MA and Kinoshita K: Does estrogen affect the development of abnormal vascular function in offspring of rats fed a low-protein diet in pregnancy? Pediatr Res 59: 784-789, 2006.

36. Liu X, El-mahdy MA, Boslett J, Varadharaj S, Hemann C, Abdelghany TM, Ismail RS, Little SC, Zhou D, Thuy LT, et al: Cytoglobin regulates blood pressure and vascular tone through nitric oxide metabolism in the vascular wall. Nat Communi 8: 14807, 2017.

37. Schepelmann M, Yarova PL, Lopez-Fernandez I, Davies TS, Brennan SC, Edwards PJ, Aggarwal A, Graça J, Rietdorf K, Matchkov V, et al: The vascular $\mathrm{Ca}^{2+}$-sensing receptor regulates blood vessel tone and blood pressure. Am J Physiol Cell Physiol 310: C193-C204, 2016. 
38. Domenicali M, Ros J, Fernandez-Varo G, Cejudo-Martín P, Crespo M, Morales-Ruiz M, Briones AM, Campistol JM, Arroyo V, Vila E, et al: Increased anandamide induced relaxation in mesenteric arteries of cirrhotic rats: Role of cannabinoid and vanilloid receptors. Gut 54: 522-527, 2005.

39. Lubomirov L, Gagov H, Petkova-Kirova P, Duridanova D, Kalentchuk VU and Schubert R: Urocortin relaxes rat tail arteries by a PKA-mediated reduction of the sensitivity of the contractile apparatus for calcium. Br J Pharmacol 134: 1564-1570, 2001.

40. Foëx P and Sear J: Hypertension: Pathophysiology and treatment Continuing Edu Anaesthesia Critical Care Pain 4: 71-75, 2004.

41. Segal SS: Regulation of blood flow in the microcirculation. Microcirculation 12: 33, 2005

42. Rapp JP: Genetic analysis of inherited hypertension in the rat. Physiol Rev 80: 135-172, 2000.

43. Piech A, Dessy C, Havaux X, Feron O and Balligand JL: Differential regulation of nitric oxide synthases and their allosteric regulators in heart and vessels of hypertensive rats. Cardiovasc Res 57: 456-467, 2003

44. Sonoyama K, Greenstein A, Price A, Khavandi K and Heagerty T: Vascular remodeling: Implications for small artery function and target organ damage. Ther Adv Cardiovasc Dis 1: 129-137, 2007.

45. Molostvov G, James S, Fletcher S, Bennett J, Lehnert H, Bland R and Zehnder D: Extracellular calcium-sensing receptor is functionally expressed in human artery. Am J Physiol Renal Physiol 293: F946-F955, 2007.

46. Wang Y and Bukoski RD: Distribution of the perivascular nerve $\mathrm{Ca}^{2+}$ receptor in rat arteries. Br J Pharmacol 125: 1397-1404, 1998

47. Northcott CA and Watts SW: Low $\left[\mathrm{Mg}^{2+}\right]$ e enhances arterial spontaneous tone via phosphatidylinositol 3-kinase in DOCA-salt hypertension. Hypertension 43: 125-129, 2004.

48. Ohanian J, Gatfield KM, Ward DT and Ohanian V: Evidence for a functional calcium-sensing receptor that modulates myogenic tone in rat subcutaneous small arteries. Am J Physiol Heart Circ Physiol 288: H1756-H1762, 2005.

49. Greenberg HZE, Jahan KS, Jian S, Ho WSV and Albert AP: The calcilytics Calhex-231 and NPS 2143 and the calcimimetic Calindol reduce vascular reactivity via inhibition of voltage-gated $\mathrm{Ca}^{2+}$ channels. Eur J Pharmacol 791: 659-668, 2016.
50. Nakagawa K, Parekh N, Koleganova N, Ritz E, Schaefer F and Schmitt CP: Acute cardiovascular effects of the calcimimetic R-568 and its enantiomer S-568 in rats. Pediatr Nephrol 24: 1385-1389, 2009.

51. Sutherland SK and Benishin CG: Regulation of parathyroid hypertensive factor secretion by $\mathrm{Ca}^{2+}$ in spontaneously hypertensive rat parathyroid cells. Am J Hypertens 17: 266-272, 2004.

52. Jensen AA and Bräuner-Osborne H: Allosteric modulation of the calcium-sensing receptor. Curr Neuropharmacol 5: 180-186, 2007.

53. Saidak Z, Brazier M, Kamel S and Mentaverri R: Agonists and allosteric modulators of the calcium-sensing receptor and their therapeutic applications. Mol Pharmacol 76: 1131-1144, 2009.

54. Thakore P and Ho WS: Vascular actions of calcimimetics: Role of $\mathrm{Ca}^{2+}$-sensing receptors versus $\mathrm{Ca}^{2+}$ influx through $\mathrm{L}$-type $\mathrm{Ca}^{2+}$ channels. Br J Pharmacol 162: 749-762, 2011.

55. Qiu HY, Henrion D and Levy BI: Endogenous angiotensin II enhances phenylephrine-induced tone in hypertensive rats. Hypertension 24: 317-321, 1994.

56. Effect of angiotensin-converting enzyme inhibition compared with conventional therapy on cardiovascular morbidity and mortality in hypertension: The Captopril Prevention Project (CAPP) randomized trial. The Captopril Prevention Project (CAPP) Study Group. Current Hyperten Rep 1: 466-467, 1999.

57. Maeso R, Navarro-Cid J, Muñoz-García R, Rodrigo E, Ruilope LM, Lahera V and Cachofeiro V: Losartan reduces phenylephrine constrictor response in aortic rings from spontaneously hypertensive rats role of nitric oxide and angiotensin II type 2 receptors. Hypertension 28: 967-972, 1996.

58. Houillier P: Calcium-sensing in the kidney. Curr Opin Nephrol Hypertens 22: 566-571, 2013.

(i) $($ This work is licensed under a Creative Commons Attribution-NonCommercial-NoDerivatives 4.0 International (CC BY-NC-ND 4.0) License. 